\title{
The transmission of vertical vibration through seats: influence of the characteristics of the human body
}

\author{
Martin G.R. Toward, Michael J. Griffin \\ Human Factors Research Unit, Institute of Sound and Vibration Research, \\ University of Southampton, Southampton, SO17 1BJ, England
}

Corresponding author address:

Professor Michael J. Griffin

Human Factors Research Unit

Institute of Sound and Vibration Research

University of Southampton

Southampton SO17 1BJ

England

Telephone: (+44) 02380592277

Facsimile: (+44) 02380592927

e-mail: M.J.Griffin@soton.ac.uk 


\section{Abstract}

The transmission of vibration through a seat depends on the impedance of the seat and the apparent mass of the seat occupant. This study was designed to determine how factors affecting the apparent mass of the body (age, gender, physical characteristics, backrest contact, and magnitude of vibration) affect seat transmissibility. The transmission of vertical vibration through a car seat was measured with 80 adults ( 41 males and 39 females aged 18 to 65 ) at frequencies between 0.6 and $20 \mathrm{~Hz}$ with two backrest conditions (no backrest and backrest), and with three magnitudes of random vibration $\left(0.5,1.0\right.$, and $1.5 \mathrm{~ms}^{-2}$ r.m.s.). Linear regression models were used to study the effects of subject physical characteristics (age, gender, and anthropometry) and features of their apparent mass (resonance frequency, apparent mass at resonance and at $12 \mathrm{~Hz}$ ) on the measured seat transmissibility. The strongest predictor of both the frequency of the principal resonance in seat transmissibility and the seat transmissibility at resonance was subject age, with other factors having only marginal effects. The transmissibility of the seat at $12 \mathrm{~Hz}$ depended on subject age, body mass index, and gender. Although subject weight was strongly associated with apparent mass, weight was not strongly associated with seat transmissibility. The resonance frequency of the seat decreased with increases in the magnitude of the vibration excitation and increased when subjects made contact with the backrest. Inter-subject variability in the resonance frequency and transmissibility at resonance was less with greater vibration excitation, but was largely unaffected by backrest contact. A lumped parameter seat-person model showed that changes in seat transmissibility with age can be predicted from changes in apparent mass with age, and that the dynamic stiffness of the seat appeared to increase with increased loading so as to compensate for increases in subject apparent mass associated with increased sitting weight.

Author Keywords: seat transmissibility; biodynamics; seats; whole-body vibration; inter-subject variability; posture; age; weight; gender 
Published as: The transmission of vertical vibration through seats: influence of the characteristics of the human body. Toward, M. G. R. \& Griffin, M. J. 19 Dec 2011 In : Journal of Sound and Vibration. 330, 26, p. 6526-6543.

\section{Highlights}

$>$ Transmissibility of a car seat measured with 80 subjects (of both genders, aged 18 to 65 years), with and without backrest. > Subject age was the strongest predictor of seat transmissibility - increased age was associated with increased resonance frequency and increased seat transmissibility at resonance. > Subject weight was not strongly associated with seat transmissibility. > Seat resonance frequency decreased with increased vibration magnitude and increased when using the backrest. 


\section{Introduction}

In a wide variety of transport environments the vibration transmitted through seats is associated with discomfort (e.g. [1]). Seats can either reduce vibration discomfort or increase vibration discomfort. The efficiency of a seat in terms of vibration discomfort depends on three factors that can vary independently: (i) the seat transmissibility (ratio of the magnitude of vibration on the seat surface to the magnitude at the seat base), (ii) the sensitivity of the body to the spectrum of vibration on the seat surface, and (iii) the spectrum of vibration at the seat base [2]. It is obvious that the construction of a seat can influence the manner in which it amplifies or attenuates the vibration (e.g. [3,4]). Additionally, because a seat and a body supported on the seat form a coupled dynamic system, the vibration transmitted through seats is also influenced by the dynamic response of the human body.

When sitting upright with no backrest support, most people exhibit a resonance in their vertical apparent mass (i.e. the ratio of the force to the acceleration as a function of vibration frequency) around $4 \mathrm{~Hz}$ [5]. When the back is partially supported by an upright backrest, there is an increase in the resonance frequency of the apparent mass [6] and an increase in the apparent mass at frequencies greater than the resonance frequency $[6,7]$. The resonance frequency in the apparent mass of the body increases when a rigid backrest is reclined $[6,8]$ but decreases when a foam backrest is reclined [6]. The vibration transmitted through a seat cushion can also be affected by backrest contact: the resonance frequency and the transmissibility at resonance increased when contact was made with the backrest of a reclined train seat [3].

The resonance frequency in the vertical apparent mass of the seated human body reduces as the magnitude of the vibration excitation increases. This non-linearity has been observed with no backrest (e.g. [5,9]), with an upright backrest [10], and when sitting with a reclined backrest [8]. The dynamic properties of seat foam have also been shown to be non-linear, with the stiffness and damping decreasing with increases in the vibration magnitude $[11,12]$. The resonance frequency in the transmissibility of a sprung cushion train seat has been reported to decrease from 3.9 to $3.3 \mathrm{~Hz}$, and the transmissibility at resonance decrease from 3.1 to 2.9 , as the magnitude of vibration increased from 0.3 to $0.6 \mathrm{~ms}^{-2}$ r.m.s. [3]. The relative contributions of 
the non-linearities in seat dynamic stiffness and the non-linearities in the apparent mass of the human body to the non-linearity in seat transmissibility are not well documented.

The physical characteristics of the human body determine the apparent mass of the body. For example, variations in the mass of the body cause large inter-subject variability in vertical apparent mass at low frequencies, but after normalisation (dividing the modulus of the apparent mass by the static mass supported on the seat) the variability is much reduced [5]. The effect of subject characteristics on the vertical apparent mass of the body has been reported for the 80 subjects (41 men and 39) used in the present study [10]. With four backrest conditions (no backrest, upright rigid, reclined rigid, reclined foam) and three vibration magnitudes $(0.5,1.0$ and $1.5 \mathrm{~ms}^{-2}$ r.m.s.), subject weight was the strongest predictor of the apparent mass at $0.6 \mathrm{~Hz}$, at resonance, and at $12 \mathrm{~Hz}$. Age, body mass index (BMI) and gender had the strongest associations with the resonance frequency in the apparent mass of the body. On average, with age increasing from 18 to 65 years, the resonance frequency increased by up to $1.7 \mathrm{~Hz}$. Likewise, with body mass index increasing from 18 to $34 \mathrm{kgm}^{-2}$, the resonance frequency decreased by up to $1.7 \mathrm{~Hz}$. With the body dynamically coupled to a seat it may be expected that characteristics of the body that influence the apparent mass of the body will also affect the transmissibility of the seat supporting the body.

Although the transmissibilities of seats are often measured with human subjects, there have been few studies of the effect of subject characteristics on the transmission of vibration through seats. The resonance frequency of a car seat and the transmissibility at resonance have been reported to be unaffected by the weight or gender of subjects, despite the sitting mass varying between $31 \mathrm{~kg}$ and $72 \mathrm{~kg}$ [13]. The dynamic stiffness of foam tends to increase as the loading on the seat increases $[11,14]$, so the absence of an effect of subject weight on seat transmissibility might be due to a proportional increase in seat dynamic stiffness with increased load on the seat surface. In a study with 15 males and 15 females, significant positive correlations were found between age and seat transmissibility at resonance and significant negative correlations were found between age the transmissibility resonance frequency within the group of females, but these correlations were not statistically significant within the group of males [3]). 
Any effects of body mass index on seat transmissibility have not previously been reported. Body mass index is correlated with body weight and, probably, the contact area with the seat, with both of these factors likely to influence the seat impedance. Age is unlikely to have a direct influence on the impedance of a seat, but changes in apparent mass associated with age may influence seat transmissibility.

Simple lumped parameter models have been found to provide close representations of the apparent mass of the human body sitting upright with no backrest contact (e.g. [12]). Furthermore, the influence of factors that modify the apparent mass of the body (e.g. backrest contact, backrest inclination, hand position, foot position, vibration magnitude) can be represented by changes in the parameters of such models [15]. By extending apparent mass models to include terms representing the dynamic stiffness and damping of the seat, lumped parameter models can also be used to represent the transmission of vibration through seats [14]. The various influences on the seat dynamic properties of the backrest, the physical characteristics of the body in the seat, and the vibration magnitude, might be derived from lumped parameter models fitted to both the apparent mass of the body and seat transmissibility. The objective of this study was to determine the manner in which the principal factors affecting the vertical apparent mass of the human body (i.e., age, weight, body mass index, gender, backrest contact, and magnitude of vibration [10]) affect the transmissibility of a seat and its dynamic stiffness. It was hypothesized that the transmissibility of a seat would be influenced by factors that influence the apparent mass of the human body and that factors that increase the compression of the seat or the area of contact with the seat (e.g. increased subject weight and increased body mass index) would increase the dynamic stiffness of the seat.

\section{Methods and procedures}

\subsection{Apparatus}


Vertical vibration was produced by a 1-metre stroke electro-hydraulic vibrator in the laboratory of the Human Factors Research Unit at the Institute of Sound and Vibration Research. Horizontal acceleration was measured at less than $5 \%$ of the vertical acceleration over the frequency range 0.125 to $25 \mathrm{~Hz}$. Subjects sat on a seat from a mid-sized family car. The backrest of the seat was inclined by 15 degrees from the vertical and the seat cushion was at $12^{\circ}$ to the horizontal, as measured using an $H$-point manikin [16]. The leading edge of the seat surface was $0.44 \mathrm{~m}$ above the vibrator platform on which subjects rested their feet.

Vertical vibration of the platform and the seat was measured using piezo-resistive accelerometers (Entran EGCSY-240D-10; Entran, Potterspury, UK). The accelerometer on the seat surface was contained within an HVLab SIT-pad [17]. The SIT-pad was located so that the ischial tuberosities were either side of the centre of the pad. The accelerometer on the platform was located directly below the SIT-pad accelerometer.

\subsection{Vibration}

Gaussian random vibration (band-limited using 8-pole Butterworth filters between 0.125 and 25 $\mathrm{Hz}$ ) with approximately flat constant bandwidth acceleration spectra was generated and analysed using an HVLab data acquisition and analysis system (version 3.81; University of Southampton, UK). Broadband random vibration was used so as to achieve high coherency at all frequencies. Different random signals were generated for each subject. The measured accelerations were acquired at 400 samples per second via $133 \mathrm{~Hz}$ anti-aliasing filters.

\subsection{Conditions}

The transmissibility of the seat was measured with each subject sitting supported by the backrest and also when sitting in a relaxed upright posture with no backrest support.

With both backrest conditions, non-linearity was investigated by measuring seat transmissibility with three magnitudes of vibration $\left(0.5,1.0\right.$, and $1.5 \mathrm{~ms}^{-2}$ r.m.s.), chosen to be broadly representative of vibration magnitudes experienced in transport. Subjects were instructed to position their feet in front of them so that the underside of their thighs just made contact with the leading edge of the seat. Subjects wore a loose fitting lap belt and had access to an emergency 
stop button. The order of presentation of conditions was randomized independently for each subject.

\subsection{Subjects}

A group of 80 adult subjects was formed to be representative of the UK car driving population (Table 1; $[18,19])$. The subjects were exposed to all conditions in a single session lasting approximately 60 minutes. Subjects gave informed consent to participate in the experiment that was approved by the Human Experimentation, Safety and Ethics Committee of the Institute of Sound and Vibration Research at the University of Southampton.

\section{TABLE 1 ABOUT HERE}

\subsection{Analysis}

Transfer functions between the platform accelerometer and the SIT-pad accelerometer were calculated using the cross-spectral density method with a frequency resolution of $0.195 \mathrm{~Hz}$. The transfer functions were determined from the ratio of the cross-spectral density of the input and output acceleration to the power spectral density of the input acceleration. Prior to the calculation of the seat transmissibility, the acceleration data were normalised to remove any DC offsets.

The seat transmissibility at the primary resonance frequency was assumed to be the greatest transmissibility over the measurement range $(0.6$ to $20 \mathrm{~Hz})$. The primary resonance frequency was defined as the frequency at which the transmissibility was greatest.

\subsection{Previously reported apparent mass measurements}

The vertical apparent masses of the 80 subjects sitting with an upright posture with no backrest were used to form a seat-person model (Section 2.8) and investigate the relation between apparent mass and seat transmissibility. The apparent masses of these subjects have been presented elsewhere and are summarised below [10].

When measuring their apparent mass, the subjects sat on the flat upper surface of a force plate secured to a rigid seat. Their feet were moved forward on the vibrator platform until their thighs were just touching the leading edge of the seat. Subject sat upright with no backrest support 
while the seat was excited with broadband random vertical vibration at three magnitudes of vibration $\left(0.5,1.0\right.$, and $1.5 \mathrm{~ms}^{-2}$ r.m.s.). Each exposure to vibration was $60 \mathrm{~s}$ in duration.

Prior to the calculation of the apparent mass, mass cancellation was performed in the time domain to remove the influence of the mass of the top plate from the measured force. The apparent mass was calculated from the ratio of the cross-spectral density between the force and acceleration at the seat, to the power spectral density of the acceleration at the seat.

\subsection{Statistical analysis}

Parametric statistics were used throughout the analysis. One-way analysis of variance (ANOVA) was used to determine overall significance of differences in features of seat transmissibility when subjects were grouped by their characteristics (i.e. size, age, gender); corrected independent samples $t$-tests were then used to compare features of the seat transmissibility between pairs of groups. Repeated measures ANOVA followed by the paired samples $t$-test was used to compare features of the seat transmissibility between conditions (i.e. between backrests and vibration magnitudes). The standard deviation was used to quantify variability in features of the seat transmissibility. Variability in seat transmissibility between conditions was tested using Levene's test of equality of variance.

Linear regression was used to identify predictors of the seat transmissibility. Initially, the associations between each physical characteristic of the subjects and the features of the seat transmissibility were separately analysed by ordinary least squares regression. Then, for each test condition (i.e. for each combination of backrest and vibration magnitude) significant predictors drawn from the physical characteristics were selected for the final regression model using the PASW stepwise procedure (PASW statistics, version 17.0). A significance level of 0.05 was used to enter and retain a variable in the model. Variables significantly associated with each dynamic characteristic for any test condition, together with age and gender, were then entered simultaneously into regression models. Quadratic terms of each of the significant variables were added in turn to the final regression models; in all instances F-tests showed that assuming a linear effect did not compromise goodness of fit $(p>0.1)$. Differences in the regression coefficients, $B$, between pairs of conditions (e.g. c1, c2) were tested using the null 
hypothesis Ho: $B_{\mathrm{c} 1}=B_{\mathrm{c} 2}$. For each independent variable in the model, $x$, first a dummy variable, $z$, was created coded 1 for $c 1$ and 0 for $c 2$, as well as a variable $z x$ that was the product of $z$ and the independent variable. Variables $x, z$, and $z x$ were then used as predictors in the regression equation. The interaction term, $z x$, tested the null hypothesis $\mathrm{Ho}: B_{\mathrm{c} 1}=B_{\mathrm{c} 2}$, significance $(p<0.05)$, indicating that the regression coefficient $B_{\mathrm{c} 1}$ was significantly different from $B_{\mathrm{c} 2}$. Beta coefficients were calculated by multiplying each of the regression coefficients $(B)$ in the multiple regression models by its standard deviation and dividing by the standard deviation of the dependent variable. Thus, a change of 1.0 standard deviations in the predictor variable resulted in a change of 1.0 standard deviations in the criterion variable.

The association of features of the seat transmissibility with features of the apparent mass and other features of the seat transmissibility were separately analysed using bivariate regression analysis.

\subsection{Lumped parameter models}

A seat-person model was used to investigate whether the effects of subject characteristics and vibration magnitude on seat transmissibility could be explained by changes in the apparent mass with these same factors.

A simple single degree-of-freedom lumped parameter model was used to fit the apparent mass (Figure 1a). The model consisted of a base frame with mass $m_{0}$ and a suspended structure represented by a single mass, $m_{1}$, connected to the base by spring stiffness, $k_{1}$, in parallel with damping, $c_{1}$. The seat transmissibility was represented by adding additional stiffness $(k)$ and damping $(c)$ to represent the dynamic properties of the seat cushion (Figure 1b). The form and relevant mathematical derivations of these models can be found elsewhere [12].

Initially, the moduli and phases of the apparent mass model were fitted to the measured individual apparent masses for each magnitude of vibration. Then, by fixing the fitted body parameters, the seat transmissibility model was fitted to each of the individual seat transmissibilities measured at a comparable magnitude to determine the seat stiffness and damping parameters. For each condition, the lumped parameter models were also fitted to the 
mean measured apparent mass and the mean measured seat transmissibility over the 80 subjects.

\section{FIGURE 1 ABOUT HERE}

The curve-fitting method used the fmincon function within the optimisation toolbox (version 3.1.1) of MATLAB (version 7.5.0.342, R2007b). The function attempts to find a constrained minimum of a function of several variables starting at an initial estimate. The target error, found by summing the squares of the errors in the modulus and the phase, was minimised. To reduce the influence of the secondary resonances, the upper boundary of the fit was restrained to 1.5 times the measured primary resonance frequency for both apparent mass and seat transmissibility. The lower boundary was set to $1.0 \mathrm{~Hz}$. Before the summation of errors, an empirically determined weighting of 10 was applied to the phase errors in the apparent mass so as to obtain good fits to both the modulus (in $\mathrm{kg}$ ) and the phase (in rad); similarly a weighting of 10 was applied to modulus errors in the seat transmissibility. The values of the target parameters were allowed to be any positive value.

Depending on the starting values of the model parameters, fmincon() can identify different local minima. In an attempt to ensure that global minima were found, the error function was minimized for 100 randomly selected sets of starting values; the set that led to the minimum total error was used. The fitted responses were compared to the measured data to check goodness of fit.

\subsection{Results}

\subsection{Inter-subject variability in seat transmissibility}

When sitting supported by the backrest and exposed to $1.0 \mathrm{~ms}^{-2}$ r.m.s. vibration, the principal resonance frequency in the seat transmissibility varied over the 80 subjects between 3.5 and 4.7 Hz, with a mean of $4.4 \mathrm{~Hz}$ (Figure 2 and Table 2). The transmissibility of the seat at resonance varied between 1.6 and 2.6 with a mean of 2.0.

\section{FIGURE 2 AND TABLE 2 ABOUT HERE}

\subsection{Effects of backrest contact}


The mean resonance frequency increased from $3.9 \mathrm{~Hz}$ to $4.4 \mathrm{~Hz}$ when subjects made contact with the backrest while exposed to $1.0 \mathrm{~ms}^{-2}$ r.m.s. $(p<0.001)$, with an increase in the seat transmissibility at resonance $(p<0.001)$, and a decrease in the transmissibility at $12 \mathrm{~Hz}$ $(p<0.001)$ (Table 2, Figure 3). The means and standard deviations of the seat transmissibility with both backrest conditions are shown in Figure 4. There were no significant differences in inter-subject variability between the two backrest conditions in the resonance frequency, the seat transmissibility at resonance, or transmissibility at $12 \mathrm{~Hz}$ (in all cases $p \geq 0.15$; Table 2).

\section{TABLE 3 AND FIGURES 3 AND 4 ABOUT HERE}

\subsection{Effects of vibration magnitude}

When there was no backrest, the mean resonance frequency decreased by $0.4 \mathrm{~Hz}$ (from 4.2 to $3.8 \mathrm{~Hz})$ as the vibration magnitude increased from 0.5 to $1.5 \mathrm{~ms}^{-2}$ r.m.s. $(p<0.001$; Table 2). With the backrest, the mean resonance frequency decreased by $0.6 \mathrm{~Hz}(4.7$ to $4.1 \mathrm{~Hz})$ as the vibration magnitude increased from 0.5 to $1.5 \mathrm{~ms}^{-2}$ r.m.s. ( $(p<0.001$; Figure 3$)$. The decrease in the resonance frequency with increasing vibration magnitude was not significantly different between the two backrest conditions $(p=0.075)$. With and without the backrest, as the vibration magnitude increased from 0.5 to $1.5 \mathrm{~ms}^{-2}$ r.m.s., there was a decrease in the transmissibility at resonance (in both cases, $p<0.001)$, but no change in the transmissibility at $12 \mathrm{~Hz}(p=0.10)$. Inter-subject variability in seat transmissibility at resonance was less with $1.5 \mathrm{~ms}^{-2}$ r.m.s. than with $0.5 \mathrm{~ms}^{-2}$ r.m.s., both when subjects were supported by a backrest and when there was no backrest ( $p<0.001$ and $p=0.048$, respectively) (Figure 4, Table 3 ). Inter-subject variability in the resonance frequency was also less with $1.5 \mathrm{~ms}^{-2}$ r.m.s. than with $0.5 \mathrm{~ms}^{-2}$ r.m.s. (in both postures, $p<0.001)$. Inter-subject variability in seat transmissibility at $12 \mathrm{~Hz}$ was not significantly affected by the vibration magnitude (in both postures, $p \geq 0.76$ ).

\subsection{Effects of subject physical characteristics}

The 80 subjects were divided into four equal groups according to their age, stature, and BMI, and into two groups according to their gender; these groups are defined in Table 4. The means and standard deviations of the resonance frequency, the seat transmissibility at resonance, and 
the seat transmissibility at $12 \mathrm{~Hz}$ were calculated for each group for the backrest condition (Table 4). The mean transmissibilities of the groups are compared in Figures 5 and 6.

\section{TABLE 4 AND FIGURES 5 AND 6 ABOUT HERE}

The resonance frequency of the seat transmissibility varied between age groups $(p<0.001)$, with differences found between all pairings of age groups ( $p \leq 0.038)$, other than between Groups 2 and $3(p=0.492)$. Seat transmissibility at resonance also varied between age groups $(p<0.001)$, with significant differences between all pairings of age groups $(p \leq 0.044)$ other than between Groups 2 and $3(p=0.735)$.

Relative to the large effects of subject age, the gender, weight, stature, and BMI had smaller effects on the principal resonance in seat transmissibility (compare Figures 5 with Figure 6). There were no significant variations in either the resonance frequency or the transmissibility at resonance between subjects categorized by gender, weight, stature, or BMI (in all cases, $p \geq 0.12)$. At $12 \mathrm{~Hz}$ there were significant variations between males and females $(p=0.003)$ and between stature groups ( $p=0.017$ ); however only the differences between stature groups 1 and $2(p=0.021)$ and groups 1 and $4(p=0.028)$ were found to be significant.

\subsection{Bivariate regression analysis}

For subjects sitting with the backrest, bivariate regression analysis showed that age was the only subject characteristic associated with the seat resonance frequency, with an increase of $0.14 \mathrm{~Hz}$ in the resonance frequency for each 10-year increase in age (Table 5; regression coefficient, $B=0.014 \mathrm{~Hz}$.year $\left.{ }^{-1} ; p=0.003\right)$. The effect of age on resonance frequency was similar without the backrest $\left(B=0.012 \mathrm{~Hz}\right.$.year ${ }^{-1}, p<0.001$; Figure 7$)$. The only physical characteristics associated with the seat transmissibility at resonance were age $\left(B=0.01\right.$ year $^{-1}, p<0.001$; Figure 8) and sitting height $\left(B=-0.011 \mathrm{~cm}^{-1}, p=0.044\right)$. Subject weight, $\mathrm{BMI}$, and knee height were associated with the seat transmissibility at $12 \mathrm{~Hz}(p \leq 0.011)$. The transmissibility of the seat at resonance was positively associated with the resonance frequency $(p<0.001)$ and negatively associated with the transmissibility at $12 \mathrm{~Hz}(p=0.001$, Table 5).

TABLE 5, FIGURE 7, AND FIGURE 8 ABOUT HERE 
Features of the seat transmissibility (measured with backrest with $1.0 \mathrm{~ms}^{-2}$ r.m.s. vibration) were regressed against features of the subject apparent mass (measured without backrest at $1.0 \mathrm{~ms}^{-2}$ r.m.s.) (Table 5). For $1.0 \mathrm{~Hz}$ increase in the resonance frequency of the apparent mass there was a $0.3 \mathrm{~Hz}$ increase in the resonance frequency of the seat transmissibility $(p<0.001)$. The seat transmissibility at resonance was greater $(p<0.001)$ and the transmissibility at $12 \mathrm{~Hz}$ was less $(p<0.002)$ with subjects having greater resonance frequencies in their apparent mass. The apparent mass at resonance was not a significant predictor of any of the seat transmissibility features $(p \geq 0.682)$.

\subsection{Multiple regression analysis}

For both backrest conditions and with all three vibration magnitudes, multiple regression models investigated how features in the seat transmissibility (resonance frequency, transmissibility at resonance, and transmissibility at $12 \mathrm{~Hz}$ ) depended on subject characteristics (Table 6). After controlling for the effects of other predictors, age was associated with the resonance frequency with both backrest conditions and all three vibration magnitudes $(p<0.001)$. The association was greatest when there was no backrest with a vibration magnitude of $1.0 \mathrm{~ms}^{-2} \mathrm{r} \cdot \mathrm{m} . \mathrm{s}(B=0.016$ Hz.year $\left.{ }^{-1}\right)$, but the slope did not differ between conditions ( $\left.p>0.293\right)$. With the backrest, the mean resonance frequency was significantly greater for the group of males than the group of females with the two lowest magnitudes of vibration ( $p=0.047, p=0.048$, respectively). Interaction variables added to the regression models showed that the effect of gender on resonance frequency was not significantly affected by backrest contact or vibration magnitude $(p \geq 0.23)$. Subject age was the only significant predictor of the seat transmissibility at resonance (in all conditions, $p<0.001$ ), with interaction variables suggesting this association was independent of backrest condition and vibration magnitude $(p \geq 0.33)$.

In addition to visual inspection of histograms and $Q-Q$ plots of each variable, the KolmogorovSmirnov test in SPSS was used to check for the degree of skew (i.e. 'non-symmetry') and kurtosis (i.e. 'peakiness') in each dependent and independent variable. These checks revealed mild negative skew in the ages of the subjects; a logarithmic transformation of 'age' was used to explore (and correct for) any effects of this skew. Regression analyses using, initially, age and 
gender, and subsequently $\log (\mathrm{age})$ and gender as predictors of seat transmissibility resonance frequency and seat transmissibility at resonance were found to produce almost identical results in terms of the statistical strength of associations. By retaining age in its original units the interpretation of the results is made easier.

\section{TABLE 6 ABOUT HERE}

Standardized regression coefficients (beta coefficients) were calculated to show the relative contribution of the significant predictors of seat transmissibility with both backrest conditions and all three magnitudes of vibration (Table 6). Age was the strongest predictor of the resonance frequency in all conditions, with gender of secondary importance. The beta coefficients suggest that age, gender and body mass index contributed in approximately equal proportions in all conditions to the variability in seat transmissibility at $12 \mathrm{~Hz}$ (Table 6). In all conditions, the $R^{2}$ values indicate the models accounted for only between 20 and $30 \%$ of the variability in the resonance frequency, the transmissibility at resonance, and the transmissibility at $12 \mathrm{~Hz}$.

\subsection{Modelled seat properties}

The two degree-of-freedom seat transmissibility model in Figure 1 provided reasonable fits to the measured seat transmissibility for each of the 80 subjects around the primary resonance for both the modulus (Figure 9) and phase (Figure 10). The fits of the apparent mass with the single degree-of-freedom model were similarly good (not shown). Between 8 and $15 \mathrm{~Hz}$ in the apparent mass, and between 6 and $12 \mathrm{~Hz}$ in the seat transmissibility, another resonance was apparent with some subjects, with the frequency and magnitude of this resonance varying between subjects. The maximum frequency for fitting the model was therefore fixed at 1.5 times the measured seat resonance frequency, as increasing the frequency range compromised the fit around the primary resonance. The use of a two degree-of-freedom apparent mass model was investigated so as to represent the second resonance but although fits to the apparent mass were improved there was no improvement in the fits to the seat transmissibility at frequencies greater than the primary resonance.

\section{FIGURE 9 AND FIGURE 10 ABOUT HERE}

\subsubsection{Fitted individual seat transmissibilities}


The derived seat stiffness was strongly associated with all subject characteristics except age

(Table 7). Subject weight was the strongest individual predictor, with the $R^{2}$ value indicating that weight accounted for $59 \%$ of the variability in the derived seat stiffness (Figure 11; $B=26.80$ $\left.\mathrm{kN} / \mathrm{m} \mathrm{kg}^{-1} ; p<0.001\right)$. The apparent mass at $0.6 \mathrm{~Hz}$, at the resonance frequency, and at $12 \mathrm{~Hz}$ were also strong predictors of seat stiffness, with these apparent mass features also strongly associated with subject weight $(p=0.001)$. No statistically significant associations were found between the derived seat stiffness and the resonance frequency of the seat, the seat transmissibility at resonance, or the seat transmissibility at $12 \mathrm{~Hz}$.

\section{TABLE 7 AND FIGURE 11 ABOUT HERE}

The derived seat damping had negative associations with gender, stature, and knee height ( $p \leq 0.05)$, but individually they only accounted for a small proportion of the variability in damping (in all cases $R^{2} \approx 7 \%$ ). The strongest predictor of seat damping was the resonance frequency in the seat transmissibility $\left(p<0.01 ; R^{2}=18 \%\right)$, with the apparent mass at $0.6 \mathrm{~Hz}$, the apparent mass at resonance, and the apparent mass at $12 \mathrm{~Hz}$ also predictors $(p \leq 0.05)$. There was no significant association between the derived seat stiffness and the derived damping.

\subsubsection{Effect of vibration magnitude on seat dynamics}

At each of the three vibration magnitudes, the model parameters were similar when the model was fitted to the mean response of the 80 subjects and the mean of the individually fitted parameters (Table 8).

\section{TABLE 8 ABOUT HERE}

The mean of the individually fitted seat stiffnesses decreased from 92.1 to $83.2 \mathrm{kN} / \mathrm{m}(14 \%)$ as the vibration magnitude increased from 0.5 to $1.5 \mathrm{~ms}^{-2}$ r.m.s. $(p<0.001$; Table 8$)$; significant differences in stiffness were found between all excitation magnitudes $(p \leq 0.012$; paired samples $t$-test). There was no effect of vibration magnitude on the derived seat damping $(p=0.584)$.

After controlling for the effects of other physical characteristics, subject weight was significantly related to seat stiffness at all three vibration magnitudes ( $p<0.001$; Table 9 , Figure 11$)$, with the association not significantly dependent on vibration magnitude $(p \geq 0.2)$. Gender was a significant 
predictor of seat stiffness at $1.0 \mathrm{~ms}^{-2}$ r.m.s. $(p=0.046)$, but the beta values suggest gender was of much less importance than weight. Gender was associated with the seat damping at all three vibration magnitudes ( $p \leq 0.017)$, but the models only accounted for a small amount of the variability in seat damping $\left(R^{2} \leq 11 \%\right)$.

\section{TABLE 9 ABOUT HERE}

\section{Discussion}

\subsection{Predictors of seat transmissibility}

Subject age was the strongest predictor of the seat transmissibility resonance frequency: from 18 to 65 years, there was a mean increase in the resonance frequency of the seat with no backrest of $0.56 \mathrm{~Hz}$ with $0.5 \mathrm{~ms}^{-2}$ r.m.s. vibration and $0.75 \mathrm{~Hz}$ with $1.5 \mathrm{~ms}^{-2}$ r.m.s. vibration. The resonance frequency in the apparent masses of the same subjects increased by $1.7 \mathrm{~Hz}$ over the range 18 to 65 years [10]. Subject age was the only subject characteristic to be significantly associated with seat transmissibility at resonance, with the mean transmissibility at resonance of the seat with backrest increasing by 0.52 with $0.5 \mathrm{~ms}^{-2}$ r.m.s. vibration and by 0.37 with 1.5 $\mathrm{ms}^{-2}$ r.m.s. vibration over the 18 to 65 year age range. Age was not a significant predictor of the apparent masses of the subjects at resonance [10]. Because the seat dynamic properties did not vary with subject age (Table 9), it seems that the effects of subject age on the seat resonance frequency were largely due to increased resonance frequency in the apparent mass with increased age.

The apparent mass resonance frequency decreases with increasing body mass index (BMI) [10], but there was no evidence of BMI affecting the resonance frequency in the seat transmissibility (Table 6). The association between the BMI and the apparent mass resonance frequency was strong when sitting with an upright rigid backrest or a reclined rigid backrest, but not so strong when sitting supported by a foam backrest or sitting with no backrest as in this study [10]. The dependence of the apparent mass on the backrest could explain the lack of association between BMI and seat transmissibility resonance frequency. There was no significant effect of BMI on the derived seat stiffness after controlling for age, gender, and weight (Table 9). It might be expected that subjects with higher BMI (after controlling for subject 
weight) would have greater contact area with the seat but also that the pressure, and hence the compression of the seat foam, would be less; these two factors can have opposing effects on seat stiffness [12], and their effects may have cancelled.

The $R^{2}$ values indicate that subject characteristics accounted for only 20 to $30 \%$ of the variability in seat transmissibility, less than subject characteristics accounted for variability in apparent mass [10]. Subject weight accounts for much of the variability in apparent mass at resonance, but after normalising with respect to sitting weight the variability in apparent mass at resonance is significantly reduced [12]. In the absence of weight as a predictor of seat transmissibility at resonance (or normalized apparent mass at resonance) the low $R^{2}$ values suggest that other unmeasured factors account for most of the variability. These factors might include variations in posture between subjects, variations in subject build (e.g. body shape and size distribution and proportion of muscle and fat) not fully reflected in the BMI, as well as changes in muscle tension.

The resonance frequency in the seat transmissibility increased by $0.3 \mathrm{~Hz}$ for every $1.0 \mathrm{~Hz}$ increase in the apparent mass resonance frequency (Table 5); this could partially explain the lower associations of age, BMI, and gender with the resonance frequency in the seat transmissibility than the resonance frequency in the apparent mass.

\subsection{Effect of subject weight}

Subject weight is a strong predictor of apparent mass at resonance and at $12 \mathrm{~Hz}$ [10], but it did not significantly affect seat transmissibility at these frequencies.

The influence of variations in apparent mass with subject weight on seat transmissibility was investigated by fixing the seat parameters in the model (to the mean of the individual fits with $1.0 \mathrm{~ms}^{-2}$ r.m.s. vibration). The seat transmissibility model was then used with the apparent mass parameters derived for each of the 80 subjects. The frequency and magnitude of the resonance in the predicted seat transmissibilities were then regressed against subject weight, after correcting for age and gender (Table 10). With increasing subject weight (i.e. 46 to $103 \mathrm{~kg}$ ), the resonance frequency in the transmissibility would be expected to decrease by about $1.0 \mathrm{~Hz}$ and the transmissibility at resonance would be expected to increase by 0.46 . However, weight was 
not associated with the predicted seat transmissibility, suggesting the seat dynamic properties changed to compensate for changes in subject weight $[11,12]$.

\section{TABLE 10 ABOUT HERE}

The dynamic stiffness of a car seat and a foam squab has been measured [14] by applying preloads to the seats through an indenter head shaped like a SIT-BAR [17]. Increasing the preload from 300 to $800 \mathrm{~N}$ increased the stiffness by $30.7 \mathrm{kN} / \mathrm{m}$ with the car seat and by 33.2 $\mathrm{kN} / \mathrm{m}$ with the foam squab. In the present study, an increase in sitting weight (increasing the force on the seat from 300 to $800 \mathrm{~N}$ ) was associated with an increase in the derived stiffness of $81.3 \mathrm{kN} / \mathrm{m}$ (Table 7). The greater increase in stiffness in this study might be explained by heavier subjects having larger contact areas with the seat surface. Wei and Griffin [14] found that the damping of the car seat was little changed by the pre-load, consistent with the absence of an effect of increased loading in the present study (Table 9).

\subsection{Effects of vibration magnitude and backrest}

The decrease in the resonance frequency in the seat transmissibility with increased magnitude of vibration is consistent with previous studies (e.g. [3]). As vibration magnitude increased from 0.5 to $1.5 \mathrm{~ms}^{-2}$ r.m.s., the apparent mass resonance frequency of the present subjects decreased from 5.3 to $4.7 \mathrm{~Hz}$ (no backrest, $1.0 \mathrm{~ms}^{-2}$ r.m.s.; [10]). The present and previous studies (e.g. [11,12]) show that seat dynamic stiffness also decreases with increasing vibration magnitude. Wei [12] measured the dynamic seat stiffness and damping of a foam squab at different vibration magnitudes using an indenter and found that with various shapes and sizes of indenter, the dynamic stiffness of the foam consistently decreased with increasing vibration magnitude. With a preload of $500 \mathrm{~N}$, and vibration increasing from $0.5 \mathrm{~ms}^{-2}$ r.m.s. to 1.5 r.m.s. the stiffness decreased between $1.3 \%$ (a buttocks-shaped indenter) to $9.1 \%$ (15-cm diameter disk indenter), compared to a decrease of $10.7 \%$ in stiffness over the same range of vibration magnitude in the present study. Consistent with this study, Wei also found no systematic change in seat damping with changes in vibration magnitude.

The contribution of the non-linearity of the human body to changes in the seat transmissibility was quantified using the seat-body model to predict seat transmissibility from subject apparent 
masses at different magnitudes while the seat parameters were fixed to the mean values for all individuals at $1.0 \mathrm{~ms}^{-2}$ r.m.s. This analysis suggested the body was the dominant cause of the nonlinearity in seat transmissibility: as the vibration magnitude increased from 0.5 to $1.5 \mathrm{~ms}^{-2}$ r.m.s., the model predicted that $0.33 \mathrm{~Hz}$ of the $0.41 \mathrm{~Hz}$ decrease in the seat transmissibility resonance frequency was caused by the non-linearity of the body.

The increase in the seat resonance frequency and the increase in the seat transmissibility at resonance when subjects made contact with a reclined backrest are consistent with other studies (e.g. [3]). There was no evidence to suggest the associations of seat transmissibility with vibration magnitude or subject physical characteristics were significantly affected by backrest contact. Changes in backrest contact and backrest inclination change the posture of the seat occupant and the dynamic response to the body (e.g. [6]) but they also alter the mechanical properties of the seat by changing the area of the body in contact with the seat and the compression of the cushion.

\subsection{Limitations of modelling}

A seat transmissibility model incorporating a two degree-of-freedom apparent mass model of the body did not reflect the seat transmissibility measured around the second resonance without compromising the fit to the primary resonance, implying deficiencies in either the simple apparent mass model or the simple seat model. Fairley and Griffin [20] reported that the apparent mass of the body measured in a rigid seat and in a car seat were similar at low frequencies but differed between 12 and $18 \mathrm{~Hz}$. Differences in seat pan inclination (e.g. [12]) or pressure distribution (e.g. [21]) might have contributed to differences between the apparent mass of the body on the rigid and compliant seats and hence the poorer fit to the second resonance of the seat transmissibility in this study. The simple seat model may also be deficient in that it assumed the stiffness and damping of the seat were independent of frequency. Although a previous study found small variations over the frequency range studied here (e.g. [14]), this may not have been the case for the seat used in this study.

3.5 Implications of the results 
The strong association between subject age and seat transmissibility implies that when testing seats or defining idealized body responses (e.g. in ISO 5982 [22]) the influence of age should be considered. The weak association between subject weight and seat transmissibility suggests that weight is of less importance than age, and that the apparent mass of the body normalised with respect to sitting weight may be sufficient to define the response of models for predicting the transmissibility of conventional foam cushion seats. Anthropodynamic dummies have been developed for testing seats in place of human subjects (e.g. [23]; [24]) and standardized dummy responses have been proposed to represent different weights of subjects (e.g. $5^{\text {th }}$ and $95^{\text {th }}$ percentiles). While seat loading can affect the dynamic performance of suspension seats (e.g. [25]) there appears to be less justification for using variable weight dummies to test conventional seats. There is considerable variation in the dynamic properties of seats and seat foams (e.g. [12]) - so while other studies have also reported no correlation between subject weight and either the resonance frequency or the transmissibility at resonance for either a sprung cushion train seat [3] or a car seat [13], further investigation seems appropriate.

\section{Conclusions}

Subject age was the strongest predictor of the resonance frequency evident in vertical seat transmissibility and the only statistically significant predictor of seat transmissibility at resonance. Increased age was associated with increased resonance frequency and increased seat transmissibility at resonance, suggesting the need to use subjects of appropriate age when measuring the transmissibility of seats. Notwithstanding the significant associations with age, regression models show that the physical characteristics of subjects only accounted for 20 to $30 \%$ of the variability in the resonance frequency and the seat transmissibility at resonance. Age, gender and body mass index were significantly associated with seat transmissibility at 12 $\mathrm{Hz}$.

Subject weight was not significantly associated with seat transmissibility, even though weight has a strong association with the apparent mass of the body at resonance and at $12 \mathrm{~Hz}$. There is evidence that seat stiffness may have increased with increased load on the seat so as to compensate for increased subject weight. 
The principal resonance frequency in the seat transmissibility reduced with increasing magnitude of vibration due to non-linearity in the apparent mass of the body and, possibly, nonlinearity in the seat. The non-linearity of the body accounted for about $80 \%$ of the $0.41 \mathrm{~Hz}$ decrease in resonance frequency as the magnitude of vibration was increased from 0.5 to 1.5 $\mathrm{ms}^{-2}$ r.m.s. The resonance frequency in the vertical seat transmissibility, and the transmissibility of the seat at resonance, increased when subjects made contact with the seat backrest.

\section{References}

[1] M. J. Griffin, Handbook of Human Vibration, Academic Press Limited, New York (1990).

[2] M.J. Griffin, The evaluation of vehicle vibration and seats, Applied Ergonomics 9 (1978) 1521.

[3] C. Corbridge, M.J. Griffin, P.R. Harborough, Seat dynamics and passenger comfort, Proceeding of the Institution of Mechanical Engineers 203 (1989) 57-64.

[4] M. Kolich, S.D. Essenmacher, J.T. McEvoy, Automotive seating: The effect of foam physical properties on occupied vertical vibration transmissibility, Journal of Sound and Vibration 281 (2005) 409-416.

[5] T.E. Fairley, M.J. Griffin, The apparent mass of the seated human body: vertical vibration. Journal of Biomechanics 22 (1989) 81-94.

[6] M.G.R. Toward, M.J. Griffin, Apparent mass of the human body in the vertical direction: Effect of seat backrest. Journal of Sound and Vibration 327 (2009) 657-669.

[7] W. Wang, S. Rakheja, P.É. Boileau, Effects of sitting postures on biodynamic response of seated occupant under vertical vibration. International Journal of Industrial Ergonomics 34 (2004) 289-306.

[8] S. Rakheja, I. Stiharu, P.É. Boileau, Seated occupant apparent mass characteristics under automotive posture and vertical vibration. Journal of Sound and Vibration 253 (2002) 57-75. [9] P. Holmlund, R. Lundström, L. Lindberg, Mechanical impedance of the human body in vertical direction. Applied Ergonomics 31 (2000) 415-422. 
[10] M.G.R. Toward, M.J. Griffin, Apparent mass of the human body in the vertical direction: inter-subject variability. Journal of Sound and vibration 330 (2011) 827-841.

[11] S.W. White, S.K. Kim, A.K. Bajaj, P. Davies, D.K. Showers, P.E. Liedtke, Experimental techniques and identification of nonlinear and viscoelastic properties of flexible polyurethane foam. Nonlinear Dynamics 22 (2000) 281-313.

[12] L. Wei, Predicting transmissibility of car seats from seat impedance and the apparent mass of the human body, PhD Thesis, University of Southampton, 2000.

[13] J.H. Varterasian, R.R. Thompson, The dynamic characteristics of automobile seats with human occupants, Society of Automotive Engineers, SAE Paper No. 770249 (1977).

[14] L. Wei, M.J. Griffin, The prediction of seat transmissibility from measures of seat impedance. Journal of Sound and Vibration 214 (1998) 121-137.

[15] M.G.R. Toward, M.J. Griffin, A variable parameter single degree-of-freedom model for predicting the effects of sitting posture and vibration magnitude on the vertical apparent mass of the human body. Industrial Health 48 (2010) 654-662.

[16] International Organization for Standardization ISO 20176, Road vehicles. H-Point machine (HPM II). Specifications and Procedure for H-point determination, International Standard, 2006.

[17] E.M. Whitham, M.J. Griffin, Measuring vibration on soft seats. Society of Automotive Engineers, SAE Paper No. 770253 (1977).

[18] S. Pheasant, C. Haslegrave, Bodyspace: Anthropometry, Ergonomics and the Design of work, Taylor \& Francis Group, USA (2006).

[19] Department of Health. Health Survey for England 2007: Adult trend tables (2008). The NHS Information Centre for health and social care.

[20] T. E. Fairley, M. J. Griffin, A test method for the prediction of seat transmissibility. Society of Automotive Engineers, SAE Paper 860046 (1986). 
[21] B. Hinz, S. Rutzel, R. Bluthner, G. Menzel, H.P. Wolfel, H. Seidel, Apparent mass of seated man - First determination with a soft seat and dynamic seat pressure distributions. Journal of Sound and Vibration 298 (2006) 704-724.

[22] International Organization for Standardization ISO 5982, Mechanical vibration and shockRange of idealized values to characterize seated-body biodynamic response under vertical vibration, International Standard, 2001.

[23] A. Cullmann, H.P. Wölfel, Design of an active vibration dummy of sitting man. Clinical Biomechanics, 16 (2001) 64-72.

[24] C.H. Lewis, M.J. Griffin, Evaluating vibration isolation of soft seat cushions using an active anthropodynamic dummy. Journal of Sound and Vibration 253 (2002) 295-311.

[25] R.M. Stayner, Aspects of the development of a test code for tractor suspension seats. British Acoustical Society BAS Paper No. 71SAG (1972). 
Published as: The transmission of vertical vibration through seats: influence of the characteristics of the human body. Toward, M. G. R. \& Griffin, M. J. 19 Dec 2011 In : Journal of Sound and Vibration. 330, 26, p. 6526-6543.

Table 1 Means and standard deviations (SD) of subject characteristics (British population in brackets).

\begin{tabular}{|c|c|c|c|c|c|c|c|c|c|}
\hline & \multicolumn{3}{|c|}{ All subjects } & \multicolumn{3}{|c|}{ Women (39 subjects) } & \multicolumn{3}{|c|}{ Men (41 subjects) } \\
\hline & Mean & SD & Range & Mean & SD & Range & Mean & SD & Range \\
\hline Age, years & 33.7 & 13.1 & $18-65$ & 33.1 & 11.2 & $19-56$ & 33.8 & 14.8 & $18-65$ \\
\hline Weight, kg & 70.5 & 13.4 & $46-103$ & $62.8\left(69.7^{a}\right)$ & 11.5 & $46-98$ & $77.1\left(83.5^{a}\right)$ & 11.3 & $58-103$ \\
\hline Stature, $\mathrm{cm}$ & 171.0 & 11.3 & 149-192 & $162.6\left(162.0^{b}\right)$ & 8.9 & $149-185$ & $178.5\left(176.0^{b}\right)$ & 7.1 & 164-192 \\
\hline Body mass index ${ }^{c}, \mathrm{kgm}^{-2}$ & 24.1 & 3.8 & $18-34$ & $23.8\left(26.8^{a}\right)$ & 4.2 & $18-34$ & $24.2\left(27.1^{a}\right)$ & 3.4 & $18-31$ \\
\hline Knee height, $\mathrm{cm}$ & 52.7 & 4.2 & $45-61$ & $50.1\left(50.0^{b}\right)$ & 3.4 & $45-61$ & $55.2\left(55.0^{b}\right.$ & 3.1 & $50-61$ \\
\hline Buttock knee length, cm & 59.6 & 4.2 & $48-69$ & $57.9\left(56.5^{b}\right)$ & 3.8 & $48-66$ & $61.0\left(59.5^{b}\right)$ & 4.0 & $56-69$ \\
\hline Sitting height, $\mathrm{cm}$ & 85.8 & 5.1 & $76-101$ & $82.7\left(85.5^{b}\right)$ & 3.4 & $76-92$ & $88.7\left(91.5^{b}\right)$ & 4.7 & $80-101$ \\
\hline
\end{tabular}

${ }^{a}$ Adults aged $16+[19]$

${ }^{b}$ Anthropometric estimates for British adults aged 19-65 [18]

${ }^{c}\left(\right.$ Body mass index, $\left.\mathrm{kgm}^{-2}\right)=($ mass, $\mathrm{kg}) /(\text { height }, \mathrm{m})^{2}$ 
Published as: The transmission of vertical vibration through seats: influence of the characteristics of the human body. Toward, M. G. R. \& Griffin, M. J. 19 Dec 2011 In : Journal of Sound and Vibration. 330, 26, p. 6526-6543.

Table 2 Effect of backrest contact and vibration magnitude on primary resonance frequencies and transmissibilities of the seats at resonance and at $12.0 \mathrm{~Hz}$. Means (and standard deviations) of 80 subjects.

\begin{tabular}{lccc}
\hline & $\begin{array}{c}\text { Resonance } \\
\text { frequency, } \mathrm{Hz}\end{array}$ & $\begin{array}{c}\text { Transmissibility } \\
\text { at resonance }\end{array}$ & $\begin{array}{c}\text { Transmissibility } \\
\text { at } 12.0 \mathrm{~Hz}\end{array}$ \\
\hline $\begin{array}{l}\text { Input magnitude (no backrest) } \\
0.5 \mathrm{~ms}^{-2} \text { r.m.s. }\end{array}$ & $4.18(0.41)$ & $1.83(0.24)$ & $0.81(0.15)$ \\
$1.0 \mathrm{~ms}^{-2}$ r.m.s. & $3.93(0.34)$ & $1.77(0.23)$ & $0.81(0.15)$ \\
$1.5 \mathrm{~ms}^{-2}$ r.m.s. & $3.76(0.32)$ & $1.76(0.21)$ & $0.81(0.17)$ \\
Input magnitude (backrest) & & & \\
$0.5 \mathrm{~ms}^{-2}$ r.m.s. & $4.67(0.38)$ & $2.14(0.30)$ & $0.72(0.16)$ \\
$1.0 \mathrm{~ms}^{-2}$ r.m.s. & $4.37(0.35)$ & $2.04(0.25)$ & $0.72(0.16)$ \\
$1.5 \mathrm{~ms}^{-2}$ r.m.s. & $4.11(0.31)$ & $1.96(0.23)$ & $0.71(0.16)$ \\
\hline
\end{tabular}


Published as: The transmission of vertical vibration through seats: influence of the characteristics of the human body. Toward, M. G. R. \& Griffin, M. J. 19 Dec 2011 In : Journal of Sound and Vibration. 330, 26, p. 6526-6543.

Table 3 Correlation coefficients, $r$, between subject physical characteristics (Pearson's correlation).

\begin{tabular}{|c|c|c|c|c|c|c|c|}
\hline & $\begin{array}{l}\text { Gender, } \\
f=0, m=1\end{array}$ & $\begin{array}{l}\text { Weight, } \\
\mathrm{kg}\end{array}$ & $\begin{array}{l}\text { Stature, } \\
\mathrm{cm}\end{array}$ & $\begin{array}{l}\mathrm{BMI} \\
\mathrm{kgm}^{-2}\end{array}$ & $\begin{array}{l}\text { Knee height, } \\
\mathrm{cm}\end{array}$ & $\begin{array}{l}\text { Buttock-knee, } \\
\mathrm{cm}\end{array}$ & $\begin{array}{l}\text { Sitting height, } \\
\mathrm{cm}\end{array}$ \\
\hline Age, years & 0.04 & 0.14 & -0.04 & $0.20^{*}$ & 0.05 & -0.04 & -0.13 \\
\hline Gender, ( $f=0 ; m=1$ ) & & $0.54^{* *}$ & $0.71^{* *}$ & 0.06 & $0.63^{\star *}$ & $0.37^{* *}$ & $0.58^{\star \star}$ \\
\hline Weight, kg & & & $0.61^{* *}$ & $0.71^{* *}$ & $0.68^{* *}$ & $0.54^{* *}$ & $0.50^{* *}$ \\
\hline Stature, $\mathrm{cm}$ & & & & -0.11 & $0.89^{\star *}$ & $0.71^{* *}$ & $0.79^{\star \star}$ \\
\hline $\mathrm{BMI}, \mathrm{kgm}^{-2}$ & & & & & 0.06 & 0.05 & -0.07 \\
\hline Knee height, $\mathrm{cm}$ & & & & & & $0.69^{\star *}$ & $0.66^{\star \star}$ \\
\hline Buttock-knee length, cm & & & & & & & $0.42^{* *}$ \\
\hline
\end{tabular}

${ }^{*} p<0.05,{ }^{* *} p<0.01,{ }^{* * *} p<0.001$. 
Table 4 Effect of subject physical characteristics on the primary seat transmissibility resonance frequency and the transmissibility at resonance and at $12.0 \mathrm{~Hz}$ (backrest support; magnitude $1.0 \mathrm{~ms}^{-2}$ r.m.s.). Means (and standard deviations) of 20 subjects, except for gender (41 males, 39 females).

\begin{tabular}{|c|c|c|c|c|}
\hline & Group & $\begin{array}{l}\text { Resonance } \\
\text { frequency, } \mathrm{Hz}\end{array}$ & $\begin{array}{l}\text { Transmissibility at } \\
\text { resonance }\end{array}$ & $\begin{array}{l}\text { Transmissibility at } \\
12.0 \mathrm{~Hz}\end{array}$ \\
\hline \multicolumn{5}{|c|}{ Age, years: Median (min, max) } \\
\hline $21(18,23)$ & 1 & $4.12(0.26)$ & $1.85(0.14)$ & $0.79(0.12)$ \\
\hline $25(24,27)$ & 2 & $4.41(0.23)$ & $2.05(0.25)$ & $0.68(0.18)$ \\
\hline $34(28,45)$ & 3 & $4.34(0.36)$ & $2.02(0.16)$ & $0.70(0.15)$ \\
\hline $52(45,65)$ & 4 & $4.61(0.35)$ & $2.22(0.28)$ & $0.70(0.15)$ \\
\hline \multicolumn{5}{|c|}{ Gender: Median (min, max) } \\
\hline Female & 1 & $4.30(0.34)$ & $2.05(0.25)$ & $0.77(0.18)$ \\
\hline Male & 2 & $4.44(0.36)$ & $2.03(0.26)$ & $0.67(0.11)$ \\
\hline \multicolumn{5}{|c|}{ Weight, kg: Median (min, max) } \\
\hline $54(46,60)$ & 1 & $4.39(0.41)$ & $2.11(0.31)$ & $0.65(0.15)$ \\
\hline $64(60,69)$ & 2 & $4.35(0.35)$ & $1.97(0.22)$ & $0.73(0.11)$ \\
\hline $74(69,80)$ & 3 & $4.36(0.34)$ & $2.02(0.25)$ & $0.81(0.20)$ \\
\hline $88(80,103)$ & 4 & $4.39(0.33)$ & $2.07(0.23)$ & $0.68(0.12)$ \\
\hline \multicolumn{5}{|c|}{ Stature, $\mathrm{cm}$ : Median (min, max) } \\
\hline $156(149,163)$ & 1 & $4.29(0.34)$ & $2.07(0.24)$ & $0.80(0.20)$ \\
\hline $167(163,171)$ & 2 & $4.48(0.38)$ & $2.11(0.30)$ & $0.66(0.16)$ \\
\hline $176(171,181)$ & 3 & $4.38(0.35)$ & $2.01(0.22)$ & $0.74(0.11)$ \\
\hline $185(181,192)$ & 4 & $4.34(0.34)$ & $1.98(0.24)$ & $0.68(0.13)$ \\
\hline \multicolumn{5}{|c|}{ BMI, kgm²: Median (min, max) } \\
\hline $20(18,21)$ & 1 & $4.50(0.32)$ & $2.08(0.28)$ & $0.66(0.13)$ \\
\hline $22(21,23)$ & 2 & $4.29(0.41)$ & $1.99(0.22)$ & $0.70(0.12)$ \\
\hline $25(24,26)$ & 3 & $4.36(0.32)$ & $2.01(0.26)$ & $0.73(0.15)$ \\
\hline $31(26,34)$ & 4 & $4.35(0.35)$ & $2.08(0.25)$ & $0.77(0.20)$ \\
\hline
\end{tabular}


Table 5 Bivariate regression coefficients showing the influence of subject physical characterises on predictors of seat transmissibility (with backrest; magnitude $1.0 \mathrm{~ms}^{-2}$ r.m.s.).

\begin{tabular}{|c|c|c|c|c|c|c|}
\hline \multirow[t]{2}{*}{ Variables } & \multicolumn{2}{|c|}{$\begin{array}{l}\text { Resonance } \\
\text { frequency, } \mathrm{Hz}\end{array}$} & \multicolumn{2}{|c|}{$\begin{array}{l}\text { Transmissibility } \\
\text { at resonance }\end{array}$} & \multicolumn{2}{|c|}{$\begin{array}{c}\text { Transmissibility } \\
\text { at } 12 \mathrm{~Hz}\end{array}$} \\
\hline & $B$ & SEB & $B$ & SEB & $B$ & SEB \\
\hline \multicolumn{7}{|l|}{ Physical characteristics } \\
\hline Age (years) & $0.014^{* * *}$ & 0.003 & $0.010 * * *$ & 0.002 & -0.002 & 0.001 \\
\hline Gender $($ female $=0 ;$ male $=1)$ & 0.000 & 0.003 & -0.001 & 0.002 & 0.001 & 0.001 \\
\hline Weight, kg & 0.144 & 0.078 & -0.023 & 0.057 & $-0.102^{* *}$ & 0.033 \\
\hline Stature, $\mathrm{cm}$ & 0.001 & 0.004 & -0.004 & 0.003 & -0.003 & 0.002 \\
\hline $\mathrm{BMI}, \mathrm{kgm}^{-2}$ & -0.004 & 0.011 & 0.006 & 0.008 & $0.012^{* *}$ & 0.005 \\
\hline Knee height, cm & 0.005 & 0.010 & -0.001 & 0.007 & $-0.011^{*}$ & 0.004 \\
\hline Buttock-knee length, cm & 0.002 & 0.010 & -0.008 & 0.007 & -0.002 & 0.004 \\
\hline Sitting height, $\mathrm{cm}$ & -0.002 & 0.008 & $-0.011^{*}$ & 0.006 & -0.004 & 0.004 \\
\hline \multicolumn{7}{|l|}{ Seat transmissibility (ST) features } \\
\hline ST resonance frequency, $\mathrm{Hz}$ & & & $0.527^{* * *}$ & 0.055 & $-0.161^{* *}$ & 0.047 \\
\hline ST at resonance & $1.027^{* * *}$ & 0.107 & & & $-0.272^{* * *}$ & 0.063 \\
\hline ST at $12 \mathrm{~Hz}$ & $-0.809 * *$ & 0.237 & $-0.700 * * *$ & 0.164 & & \\
\hline \multicolumn{7}{|l|}{ Apparent mass (APM) features } \\
\hline APM resonance frequency, $\mathrm{Hz}$ & $0.300 * * *$ & 0.059 & $0.199 * * *$ & 0.043 & $-0.094^{* *}$ & 0.028 \\
\hline APM at resonance, $\mathrm{kg}$ & -0.001 & 0.002 & 0.000 & 0.001 & 0.000 & 0.001 \\
\hline APM at $12 \mathrm{~Hz}, \mathrm{~kg}$ & 0.016 ** & 0.006 & 0.008 & 0.004 & -0.001 & 0.003 \\
\hline
\end{tabular}

Abbreviations: $B$, regression coefficient; $S E B$, standard error of the regression coefficient. ${ }^{\star} p<0.05,{ }^{* \star} p<0.01,{ }^{* \star *} p<0.001$. 
Table 6 Multiple regression analysis showing the influence of vibration magnitude and backrest condition on predictors of seat transmissibility.

\begin{tabular}{|c|c|c|c|c|c|c|c|c|c|}
\hline & \multicolumn{3}{|c|}{$0.5 \mathrm{~ms}^{-2}$ r.m.s. } & \multicolumn{3}{|c|}{$1.0 \mathrm{~ms}^{-2}$ r.m.s. } & \multicolumn{3}{|c|}{$1.5 \mathrm{~ms}^{-2}$ r.m.s. } \\
\hline & $B p$ & SEB & $\beta$ & $B$ & SEB & $\beta$ & $B$ & SEB & $\beta$ \\
\hline \multicolumn{10}{|l|}{ Backrest } \\
\hline \multicolumn{10}{|l|}{ Resonance frequency, $\mathrm{Hz}$} \\
\hline Age (years) & $0.012^{* * *}$ & 0.003 & 0.40 & $0.013^{* * *}$ & 0.003 & 0.50 & $0.012^{* * *}$ & 0.002 & 0.51 \\
\hline Gender $($ female $=0 ;$ male $=1$ ) & 0.154 * & 0.076 & 0.20 & $0.136^{*}$ & 0.067 & 0.19 & 0.035 & 0.061 & 0.06 \\
\hline Constant & 4.195 & & & 3.849 & & & 3.676 & & \\
\hline$R^{2}, \%$ & 20.7 & & & 28.9 & & & 26.6 & & \\
\hline \multicolumn{10}{|l|}{ Resonance magnitude } \\
\hline Age (years) & $0.011^{* * *}$ & 0.002 & 0.47 & $0.010^{* * *}$ & 0.002 & 0.53 & $0.008^{* * *}$ & 0.002 & 0.46 \\
\hline Gender (female $=0 ;$ male $=1$ ) & -0.031 & 0.059 & -0.05 & -0.029 & 0.048 & -0.06 & -0.023 & 0.046 & -0.05 \\
\hline Constant & 1.791 & & & 1.709 & & & 1.701 & 0.067 & \\
\hline$R^{2}, \%$ & 22.6 & & & 28.3 & & & 21.4 & & \\
\hline \multicolumn{10}{|l|}{ Transmissibility at $12 \mathrm{~Hz}$} \\
\hline Age (years) & $-0.003 *$ & 0.001 & -0.24 & $-0.003^{* *}$ & 0.001 & -0.27 & $-0.004^{* *}$ & 0.001 & -0.30 \\
\hline Gender (female $=0 ;$ male $=1$ ) & $-0.110 * *$ & 0.032 & -0.34 & $-0.107^{* *}$ & 0.031 & -0.34 & $-0.105^{\star *}$ & 0.030 & -0.33 \\
\hline $\mathrm{BMI}, \mathrm{kgm}^{-2}$ & $0.014^{* *}$ & 0.004 & 0.32 & $0.016^{* * *}$ & 0.004 & 0.37 & $0.016^{* * *}$ & 0.004 & 0.37 \\
\hline Constant & 0.544 & & & 0.508 & & & 0.513 & & \\
\hline$R^{2}, \%$ & 24.1 & & & 27.5 & & & 28.8 & & \\
\hline \multicolumn{10}{|l|}{ No backrest contact } \\
\hline \multicolumn{10}{|l|}{ Resonance frequency, $\mathrm{Hz}$} \\
\hline Age (years) & $0.016^{* * *}$ & 0.003 & 0.51 & $0.012^{* * *}$ & 0.003 & 0.46 & $0.012^{* * *}$ & 0.002 & 0.50 \\
\hline Gender $($ female $=0 ;$ male $=1)$ & 0.109 & 0.078 & 0.13 & 0.040 & 0.067 & 0.06 & 0.042 & 0.062 & 0.07 \\
\hline Constant & 3.587 & & & 3.504 & & & 3.333 & & \\
\hline$R^{2}, \%$ & 28.4 & & & 21.8 & & & 25.6 & & \\
\hline \multicolumn{10}{|l|}{ Resonance magnitude } \\
\hline Age (years) & $0.010 * * *$ & 0.002 & 0.52 & $0.009^{* * *}$ & 0.002 & 0.52 & $0.008^{* * *}$ & 0.002 & 0.49 \\
\hline Gender $($ female $=0 ;$ male $=1$ ) & 0.029 & 0.046 & 0.06 & -0.022 & 0.044 & -0.05 & -0.045 & 0.041 & -0.11 \\
\hline Constant & 1.488 & & & 1.472 & & & 1.515 & & \\
\hline$R^{2}, \%$ & 27.7 & & & 26.8 & & & 25.1 & & \\
\hline \multicolumn{10}{|l|}{ Transmissibility at $12 \mathrm{~Hz}$} \\
\hline Age (years) & $-0.004^{* *}$ & 0.001 & -0.33 & $-0.004^{* *}$ & 0.001 & -0.36 & $-0.005^{* * *}$ & 0.001 & -0.41 \\
\hline Gender $($ female $=0 ;$ male $=1)$ & $-0.111^{* * *}$ & 0.030 & -0.36 & $-0.082^{* *}$ & 0.031 & -0.27 & $-0.103^{* *}$ & 0.032 & -0.31 \\
\hline $\mathrm{BMI}, \mathrm{kgm}^{-2}$ & 0.009 * & 0.004 & 0.22 & $0.010^{*}$ & 0.004 & 0.23 & $0.014^{* *}$ & 0.004 & 0.30 \\
\hline Constant & 0.780 & & & 0.758 & & & 0.712 & & \\
\hline$R^{2}, \%$ & 26.2 & & & 22.0 & & & 30.1 & & \\
\hline
\end{tabular}

Abbreviations: $B$, regression coefficient; SEB, standard error of the regression coefficient; $\beta$, standardized regression coefficient; $R^{2}$ : percentage of experimental variation accounted for by the model.

${ }^{*} p<0.05,{ }^{* *} p<0.01,{ }^{* * *} p<0.001$. 
Table 7 Bivariate regression coefficients showing factors influencing the derived seat stiffness and damping (seat transmissibilities and apparent masses measured with no backrest at $1.0 \mathrm{~ms}^{-2}$ r.m.s.).

\begin{tabular}{|c|c|c|c|c|c|c|}
\hline \multirow[t]{2}{*}{ Variables } & \multicolumn{3}{|c|}{$K, \mathrm{kN} / \mathrm{m}$} & \multicolumn{3}{|c|}{$C, \mathrm{Ns} / \mathrm{m}$} \\
\hline & $B$ & $S E B$ & $R^{2}, \%$ & $B$ & SEB & $R^{2}, \%$ \\
\hline \multicolumn{7}{|l|}{ Physical characteristics } \\
\hline Age (years) & 0.20 & 223 & 1.1 & -1 & 6 & 0.1 \\
\hline Gender (female $=0 ;$ male $=1$ ) & $1.47^{* * *}$ & 4954 & 27.8 & 366 * & 150 & 7.3 \\
\hline Weight, kg & $26.80^{* * *}$ & 139 & 59.4 & 9 & 6 & 2.8 \\
\hline Stature, $\mathrm{cm}$ & $1.25^{* * *}$ & 216 & 30.6 & $16^{*}$ & 7 & 7.4 \\
\hline $\mathrm{BMI}, \mathrm{kgm}^{-2}$ & $3.19 * * *$ & 690 & 22.0 & -10 & 21 & 0.3 \\
\hline Knee height, cm & $3.58^{* * *}$ & 578 & 33.6 & $45^{*}$ & 18 & 7.3 \\
\hline Buttock-knee length, cm & 2.31 ** & 646 & 14.4 & 16 & 19 & 0.9 \\
\hline Sitting height, $\mathrm{cm}$ & $2.45^{* * *}$ & 505 & 23.7 & 28 & 15 & 4.4 \\
\hline \multicolumn{7}{|l|}{ Seat transmissibility (ST) features } \\
\hline ST resonance frequency, $\mathrm{Hz}$ & 11.93 & 9370 & 2.1 & -678 ** & 241 & 9.5 \\
\hline ST at resonance & -0.36 & 14187 & 0.0 & $-1375^{* * *}$ & 345 & 17.5 \\
\hline $\mathrm{ST}$ at $12 \mathrm{~Hz}$ & 8.25 & 17331 & 0.3 & 34 & 464 & 0.0 \\
\hline \multicolumn{7}{|l|}{ Apparent mass (APM) features } \\
\hline APM resonance frequency, $\mathrm{Hz}$ & 0.46 & 4893 & 0.0 & 215 & 129 & 3.6 \\
\hline APM at $0.6 \mathrm{~Hz}, \mathrm{~kg}$ & $1.60^{* * *}$ & 144 & 61.7 & $17^{* *}$ & 6 & 10.0 \\
\hline $\mathrm{APM}$ at resonance, $\mathrm{kg}$ & $0.82^{* * *}$ & 70 & 64.5 & 9 ** & 3 & 10.1 \\
\hline APM at $12 \mathrm{~Hz}, \mathrm{~kg}$ & $1.59 * * *$ & 402 & 17.0 & 24 * & 11 & 5.5 \\
\hline \multicolumn{7}{|l|}{ Seat dynamic properties } \\
\hline$K, \mathrm{kN} / \mathrm{m}$ & & & & 2 & 4 & 0.4 \\
\hline$C, \mathrm{Ns} / \mathrm{m}$ & 0.00 & 4 & 0.4 & & & \\
\hline
\end{tabular}

Abbreviations: $B$, regression coefficient; SEB, standard error of the regression coefficient; $R^{2}$ : percentage of experimental variation accounted for by the model.

${ }^{*} p<0.05,{ }^{* *} p<0.01,{ }^{* \star *} p<0.001$. 
Published as: The transmission of vertical vibration through seats: influence of the characteristics of the human body. Toward, M. G. R. \& Griffin, M. J. 19 Dec 2011 In : Journal of Sound and Vibration. 330, 26, p. 6526-6543.

Table 8 Effect of vibration magnitude on the parameters of the seat transmissibility model.

\begin{tabular}{lllllll}
\hline & $K, \mathrm{kN} / \mathrm{m}$ & $C, \mathrm{Ns} / \mathrm{m}$ & $m_{0}, \mathrm{~kg}$ & $m_{1}, \mathrm{~kg}$ & $k_{1}, \mathrm{kN} / \mathrm{m}$ & $\mathrm{c}_{1}, \mathrm{Ns} / \mathrm{m}$ \\
\hline Fitted to mean & & & & & & \\
$0.5 \mathrm{~ms}^{-2}$ r.m.s. & 97.4 & 831 & 9.4 & 50.8 & 67083 & 1495 \\
$1.0 \mathrm{~ms}^{-2}$ r.m.s. & 89.7 & 777 & 9.5 & 50.4 & 56927 & 1386 \\
$1.5 \mathrm{~ms}^{-2}$ r.m.s. & 83.6 & 774 & 9.2 & 50.8 & 53491 & 1338 \\
Mean of fits to individuals & & & & & & \\
$0.5 \mathrm{~ms}^{-2}$ r.m.s. & 92.1 & 829 & 13.1 & 44.8 & 59799 & 1318 \\
$1.0 \mathrm{~ms}^{-2}$ r.m.s. & 88.7 & 783 & 11.5 & 48.5 & 55583 & 1301 \\
$1.5 \mathrm{~ms}^{-2}$ r.m.s. & 83.2 & 791 & 11.1 & 49.2 & 52700 & 1256 \\
\hline
\end{tabular}


Table 9 Multiple regression analysis showing the influence of vibration magnitude on predictors of derived seat dynamic properties (apparent masses and seat transmissibility measured with no backrest contact at $1.0 \mathrm{~ms}^{-2}$ r.m.s.).

\begin{tabular}{|c|c|c|c|c|c|c|c|c|c|}
\hline & \multicolumn{3}{|c|}{$0.5 \mathrm{~ms}^{-2}$ r.m.s. } & \multicolumn{3}{|c|}{$1.0 \mathrm{~ms}^{-2}$ r.m.s. } & \multicolumn{3}{|c|}{$1.5 \mathrm{~ms}^{-2}$ r.m.s. } \\
\hline & $p$ & SEB & $\beta$ & $p$ & SEB & $\beta$ & $B$ & SEB & $\beta$ \\
\hline \multicolumn{10}{|l|}{ Seat stiffness $K, \mathrm{kN} / \mathrm{m}$} \\
\hline Age (years) & 0.15 & 157 & 0.08 & -0.04 & 143 & -0.02 & 0.21 & 132 & 0.12 \\
\hline Gender (female $=0 ;$ male $=1$ ) & 4.56 & 4829 & 0.09 & $8.73^{*}$ & 4294 & 0.17 & 6.56 & 4022 & 0.15 \\
\hline Weight $(\mathrm{kg})$ & $1.35^{* * *}$ & 185 & 0.68 & $1.32^{* * *}$ & 166 & 0.68 & $1.10^{* * *}$ & 153 & 0.65 \\
\hline Constant & -11.18 & & & -7.49 & & & -4.86 & & \\
\hline$R^{2}, \%$ & 55.8 & & & 61.6 & & & 57.2 & & \\
\hline \multicolumn{10}{|l|}{ Seat damping $C, N / m$} \\
\hline Age (years) & -1 & 5 & -0.01 & -2 & 6 & -0.04 & 0 & 4 & -0.01 \\
\hline Gender $($ female $=0 ;$ male $=1$ ) & $368^{* *}$ & 134 & 0.30 & $369^{*}$ & 151 & 0.27 & $350 * *$ & 115 & 0.33 \\
\hline Constant & 615 & & & 663 & & & 618 & & \\
\hline$R^{2}, \%$ & 9.1 & & & 7.4 & & & 10.9 & & \\
\hline
\end{tabular}

Abbreviations: $B$, regression coefficient; SEB, standard error of the regression coefficient; $\beta$, standardized regression coefficient; $R^{2}$ : percentage of experimental variation accounted for by the model.

${ }^{*} p<0.05,{ }^{* *} p<0.01,{ }^{* * *} p<0.001$. 
Table 10 Multiple regression analysis of predictors of seat transmissibility features where seat parameters are assumed to be independent of physical characteristic (apparent masses and seat transmissibility measured with no backrest contact at $1.0 \mathrm{~ms}^{-2}$ r.m.s.).

\begin{tabular}{|c|c|c|c|c|c|c|c|c|}
\hline & \multicolumn{4}{|c|}{$\begin{array}{c}\text { Resonance } \\
\text { frequency, } \mathrm{Hz}\end{array}$} & \multicolumn{4}{|c|}{$\begin{array}{l}\text { Transmissibility } \\
\text { at resonance }\end{array}$} \\
\hline & $B$ & $p$ & SEB & $\beta$ & $B$ & $p$ & SEB & $\beta$ \\
\hline Age (years) & \multicolumn{2}{|c|}{$0.015^{\star \star *}$} & 0.002 & 0.558 & \multicolumn{2}{|c|}{$0.007^{* * *}$} & 0.002 & 0.311 \\
\hline Gender (female $=0 ;$ male $=1$ ) & \multicolumn{2}{|c|}{$0.221^{* *}$} & 0.070 & 0.304 & \multicolumn{2}{|c|}{$0.222^{* *}$} & 0.061 & 0.351 \\
\hline Weight $(\mathrm{kg})$ & \multirow{2}{*}{\multicolumn{2}{|c|}{$\begin{array}{r}-0.010 \\
4.182\end{array}$}} & 0.003 & -0.642 & \multirow{2}{*}{\multicolumn{2}{|c|}{$\begin{array}{l}0.008 \\
0.825\end{array}$}} & 0.002 & 0.343 \\
\hline Constant & & & & & & & & \\
\hline$R^{2}, \%$ & \multicolumn{2}{|c|}{51.0} & & & \multicolumn{2}{|c|}{50.4} & & \\
\hline
\end{tabular}

Abbreviations: $B$, regression coefficient; SEB, standard error of the regression coefficient; $\beta$, standardized regression coefficient; $R^{2}$ : percentage of experimental variation accounted for by the model.

${ }^{* *} p<0.01,{ }^{* * *} p<0.001$ 
Published as: The transmission of vertical vibration through seats: influence of the characteristics of the human body. Toward, M. G. R. \& Griffin, M. J. 19 Dec 2011 In : Journal of Sound and Vibration. 330, 26, p. 6526-6543.
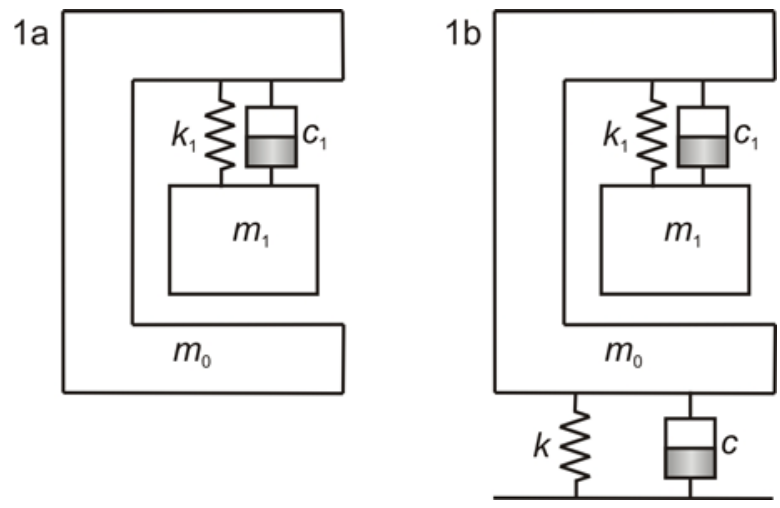

Figure 1 Apparent mass model (1a) and seat transmissibility model (1b). 
Published as: The transmission of vertical vibration through seats: influence of the characteristics of the human body. Toward, M. G. R. \& Griffin, M. J. 19 Dec 2011 In : Journal of Sound and Vibration. 330, 26, p. 6526-6543.

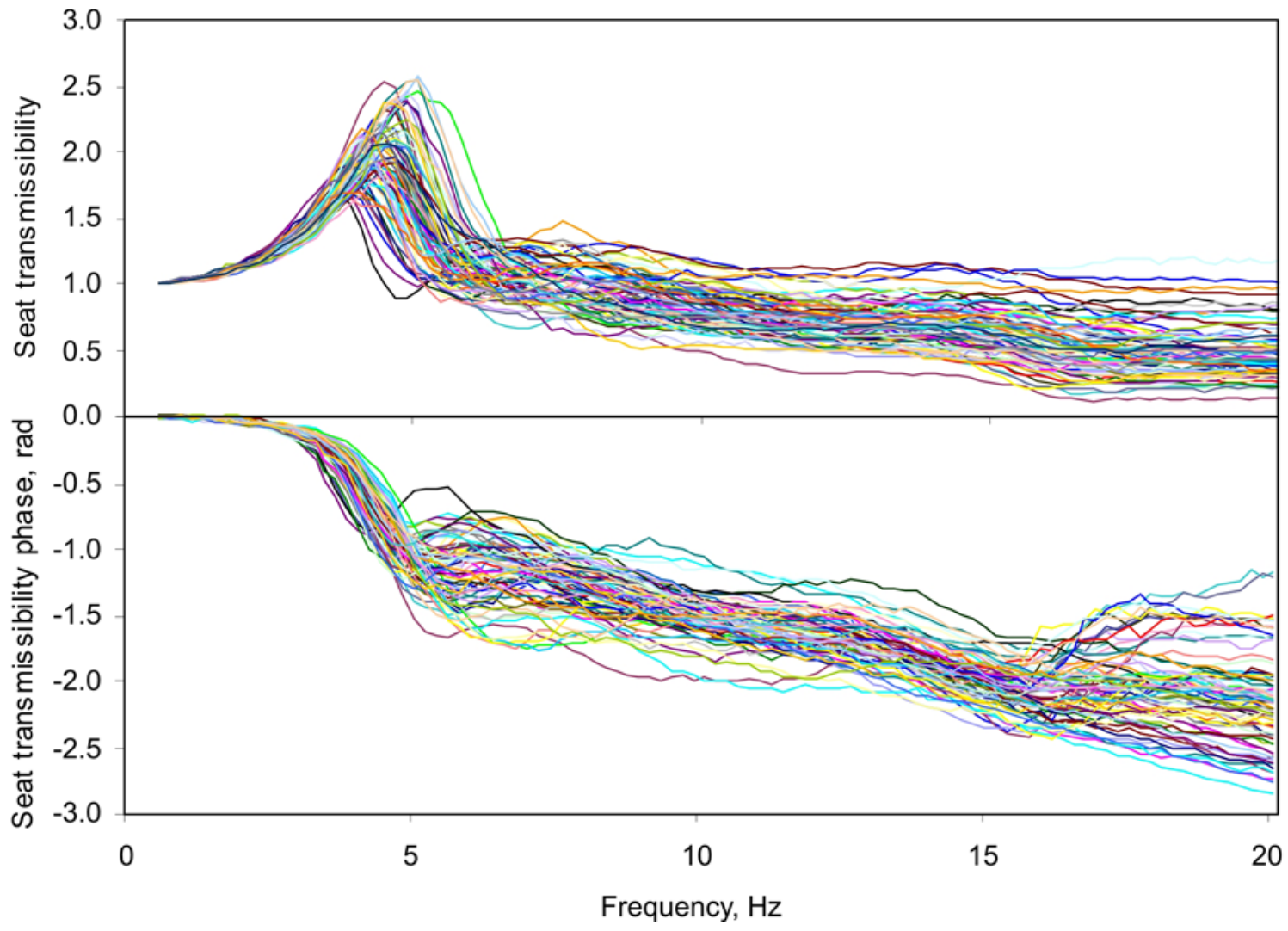

Figure 2 Seat transmissibilities for 80 people (backrest; vibration magnitude 1.0 ms $^{-2}$ r.m.s.). 
Published as: The transmission of vertical vibration through seats: influence of the characteristics of the human body. Toward, M. G. R. \& Griffin, M. J. 19 Dec 2011 In : Journal of Sound and Vibration. 330, 26, p. 6526-6543.

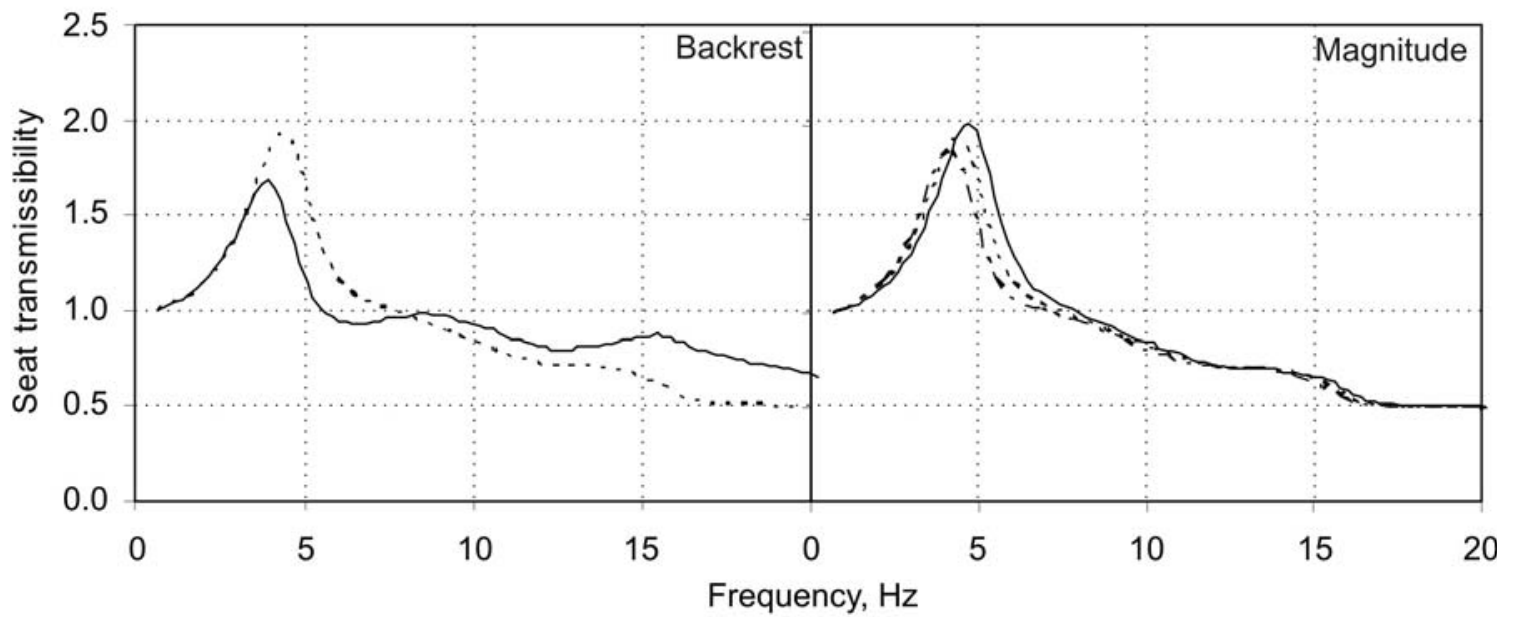

Figure 3 Effect of backrest (No backrest ,_—_ Backrest, $\cdots \cdots)$ and input magnitude $\left(0.5 \mathrm{~ms}^{-2}\right.$ r.m.s., — $; 1.0 \mathrm{~ms}^{-2}$ r.m.s., $\cdots \cdot ; 1.5 \mathrm{~ms}^{-2}$ r.m.s., $\left.\cdot-\cdot-\right)$ on seat transmissibility. 


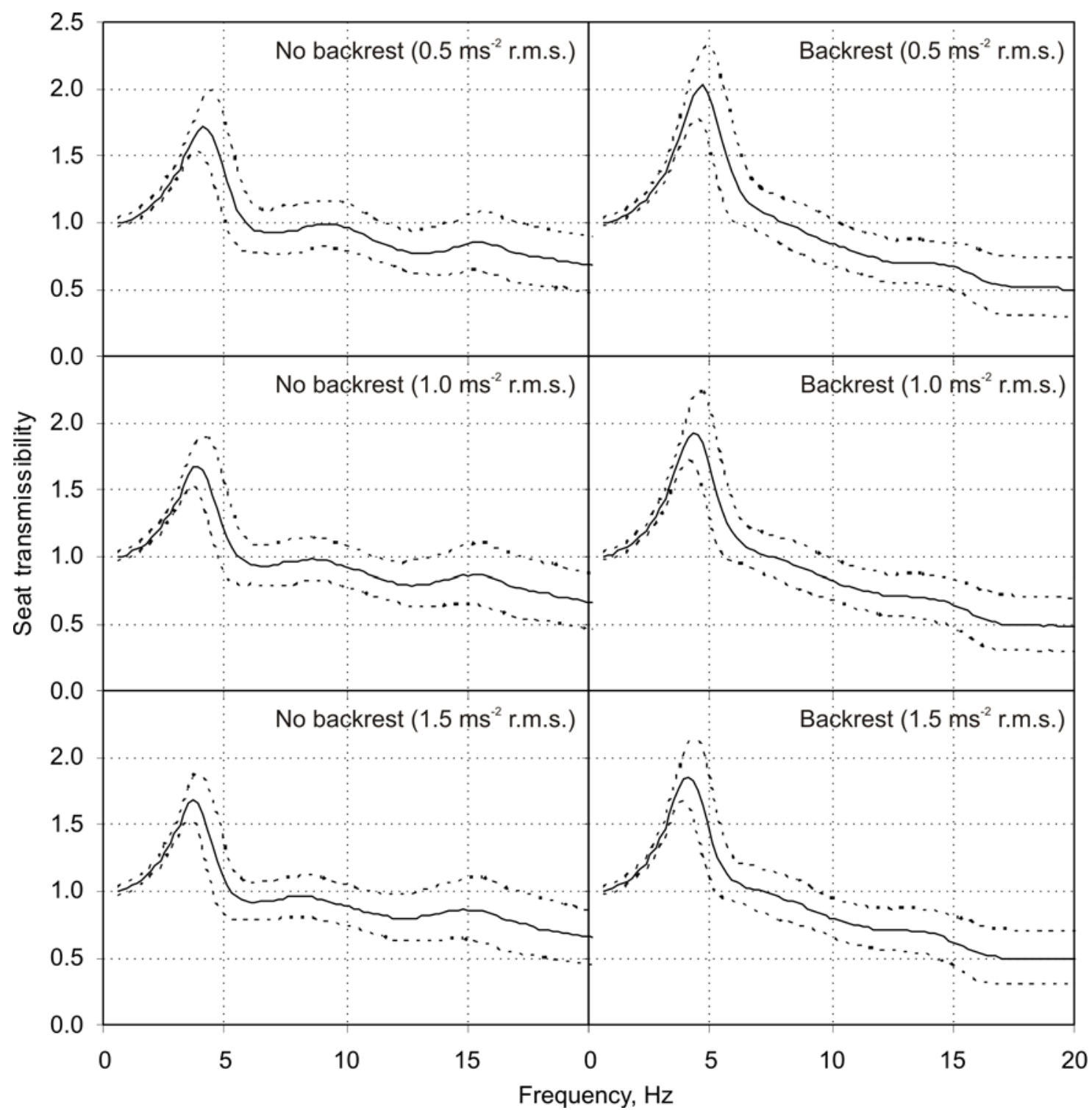

Figure 4 Effect of the seat backrest and vibration magnitude on mean apparent mass and intersubject variability: mean $(-)$ and mean $\pm \operatorname{SD}(\cdots)$ ). 
Published as: The transmission of vertical vibration through seats: influence of the characteristics of the human body. Toward, M. G. R. \& Griffin, M. J. 19 Dec 2011 In : Journal of Sound and Vibration. 330, 26, p. 6526-6543.

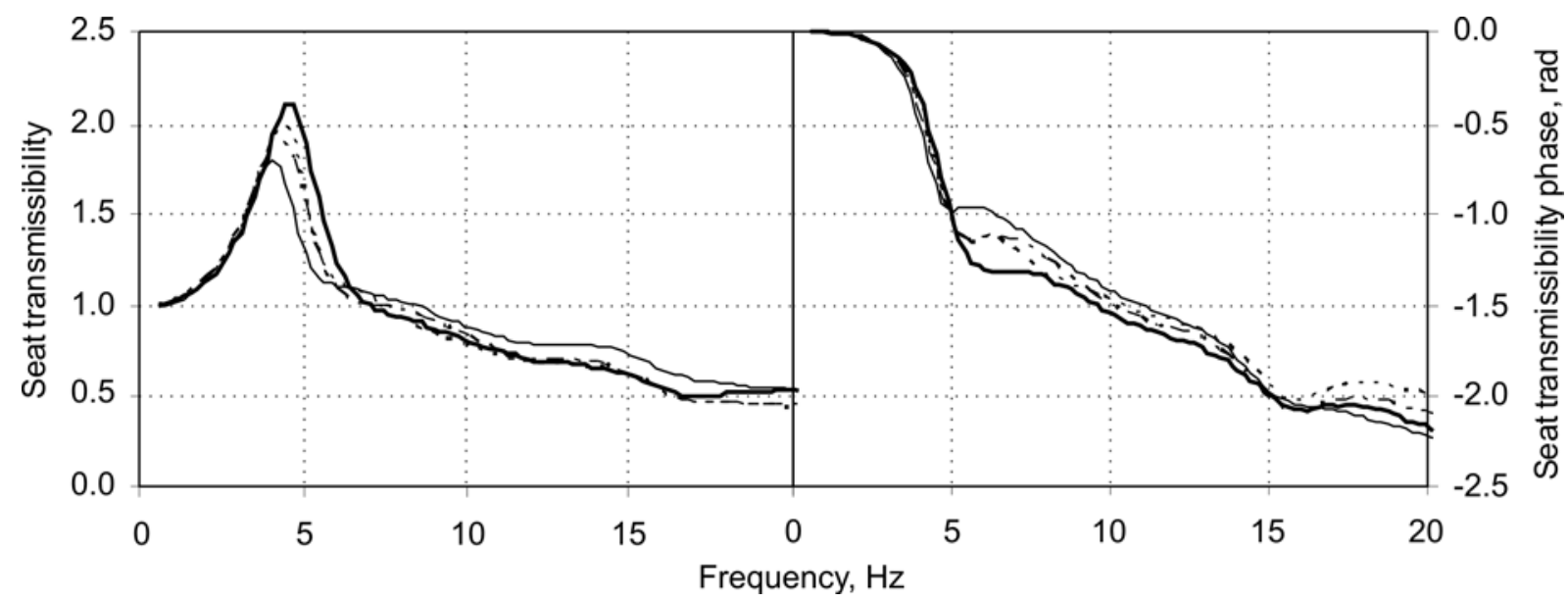

Figure 5 Effect of subject age on seat transmissibility (backrest; $1.0 \mathrm{~ms}^{-2}$ r.m.s excitation); subjects grouped by age (20 per group) with mean age: 21 years $(-), 25$ years $(\cdots \cdots), 34$ years $(\cdot-\cdot-)$ and 52 years $(-)$. 
Published as: The transmission of vertical vibration through seats: influence of the characteristics of the human body. Toward, M. G. R. \& Griffin, M. J. 19 Dec 2011 In : Journal of Sound and Vibration. 330, 26, p. 6526-6543.

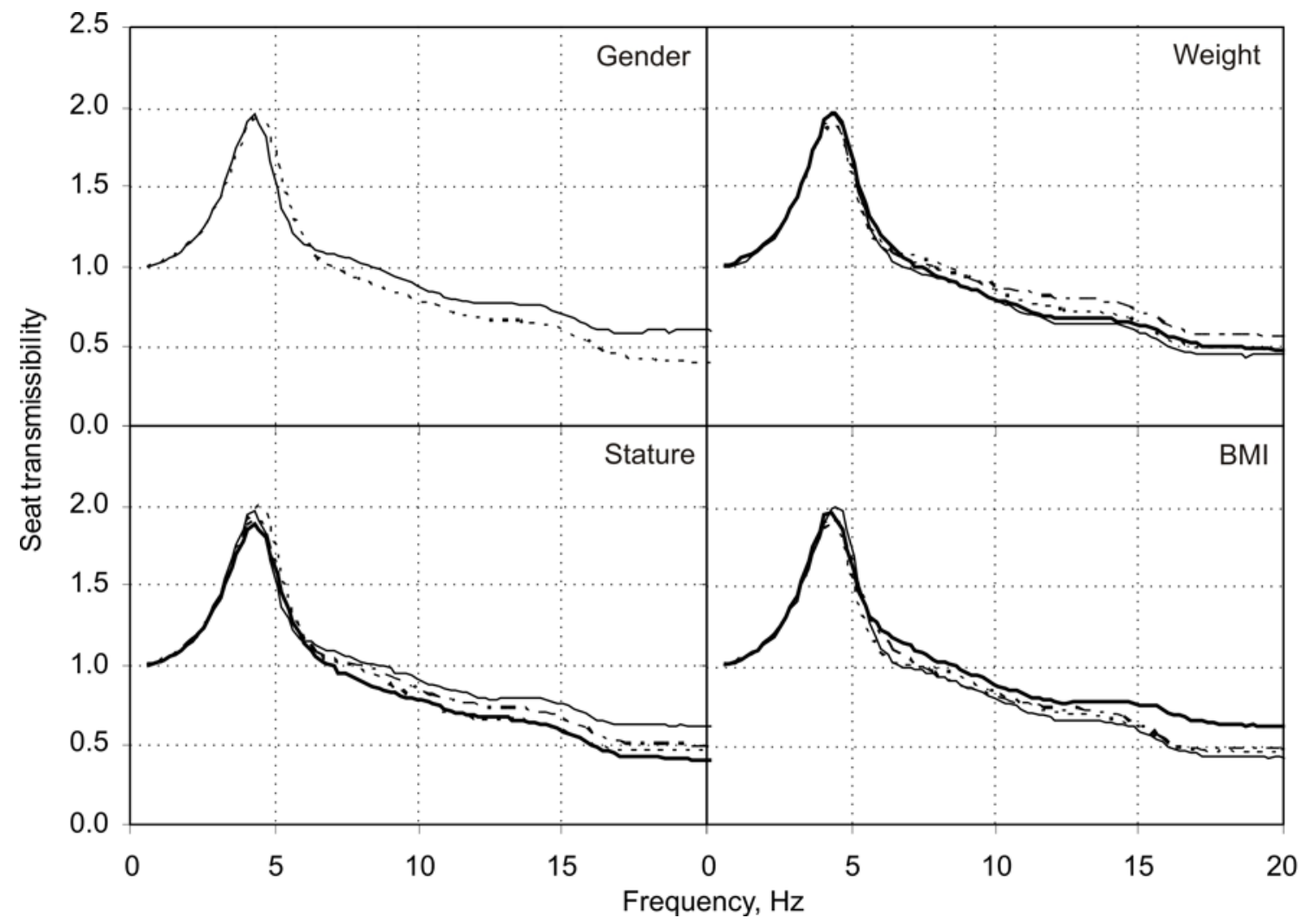

Figure 6 Effect of physical characteristics on seat transmissibility (with backrest; $1.0 \mathrm{~ms}^{-2}$ r.m.s excitation); subjects grouped (see Table 4 for details) by physical characteristic: Group 1 ( - ), Group $2(\cdot \cdots)$, Group $3(\cdot-\cdot-)$ and Group $4(-)$. 


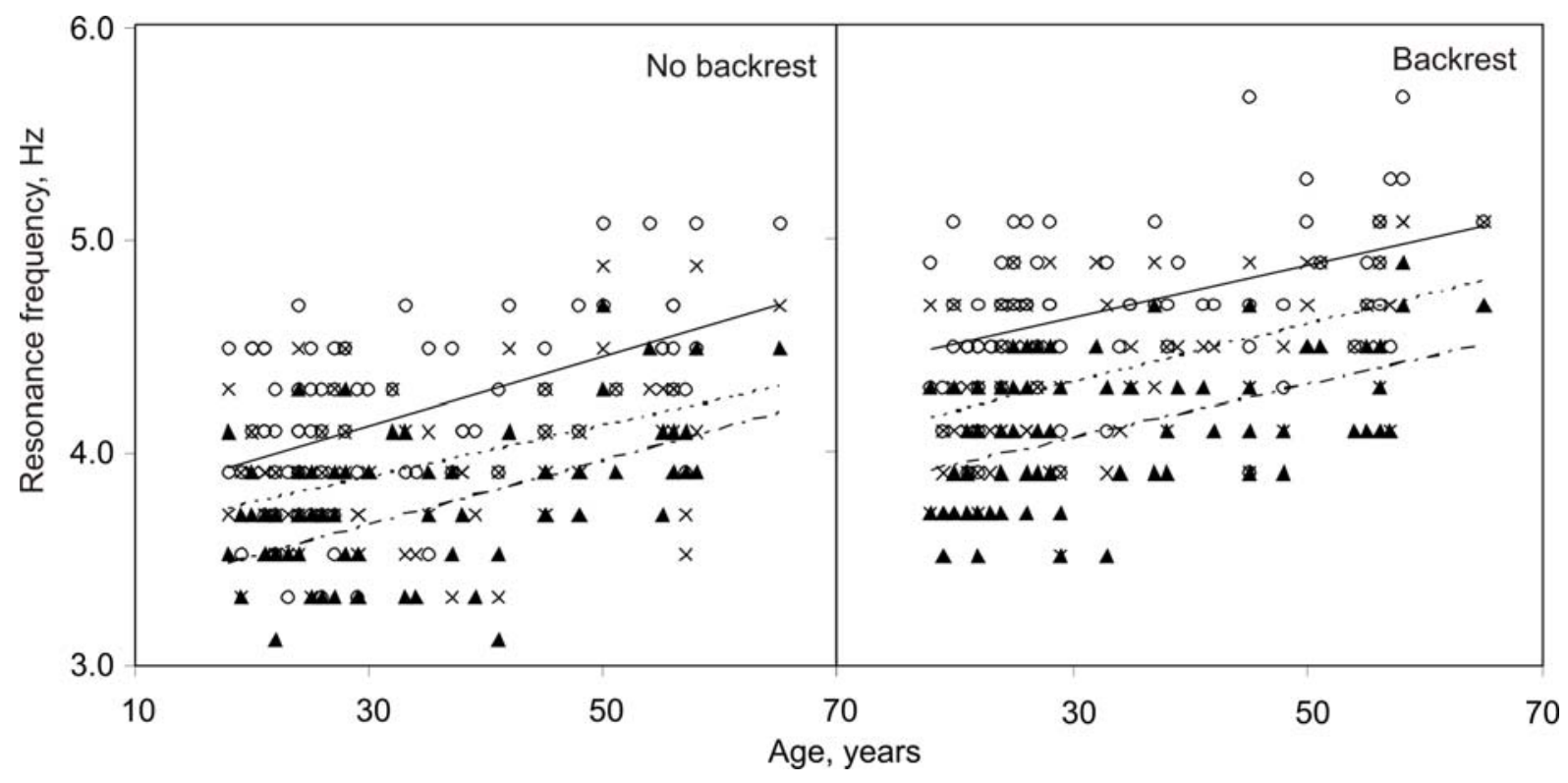

Figure 7 Effect of subject age on the seat transmissibility resonance frequency measured with 80 people at three magnitudes of excitation (no backrest and backrest): $0.5 \mathrm{~ms}^{-2}$ r.m.s. ( 0 ), $1.0 \mathrm{~ms}^{-}$ ${ }^{2}$ r.m.s. $(\times)$ and $1.5 \mathrm{~ms}^{-2}$ r.m.s. ( $\Delta$ ). Bivariate regression trend lines are also shown: $0.5 \mathrm{~ms}^{-2}$ r.m.s. $(\longrightarrow), 1.0 \mathrm{~ms}^{-2}$ r.m.s. $(\cdots)$ ) and $1.5 \mathrm{~ms}^{-2}$ r.m.s. $(\cdot-\cdot-)$. 

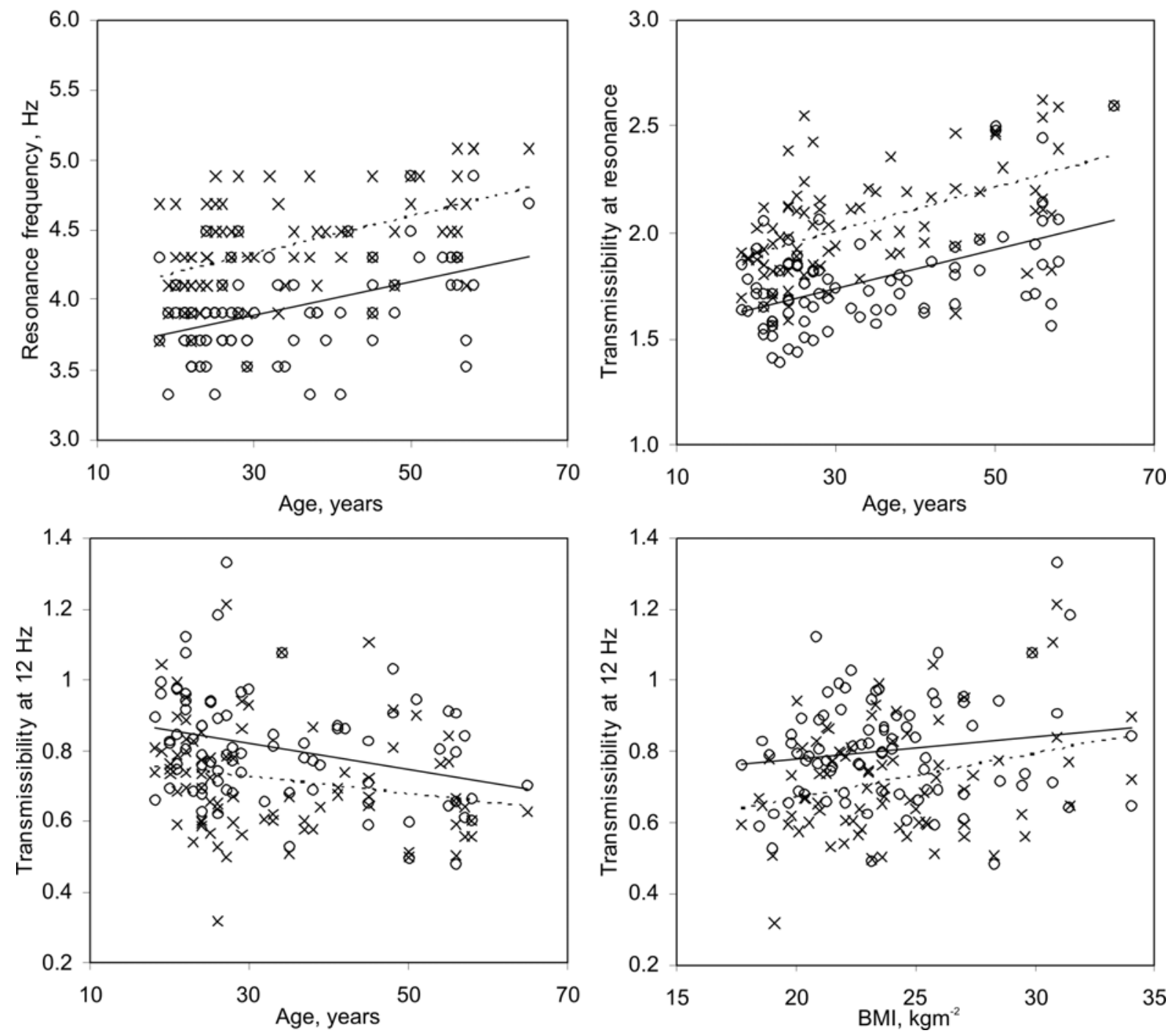

Figure 8 Effect of age and body mass index on seat transmissibility features measured with 80 people with two different backrest conditions $\left(1.0 \mathrm{~ms}^{-2}\right.$ r.m.s. excitation): no backrest $(\circ)$, backrest $(\times)$. Bivariate regression trend lines are also shown: no backrest $(-)$, backrest $(\cdots$ $\cdot)$. 


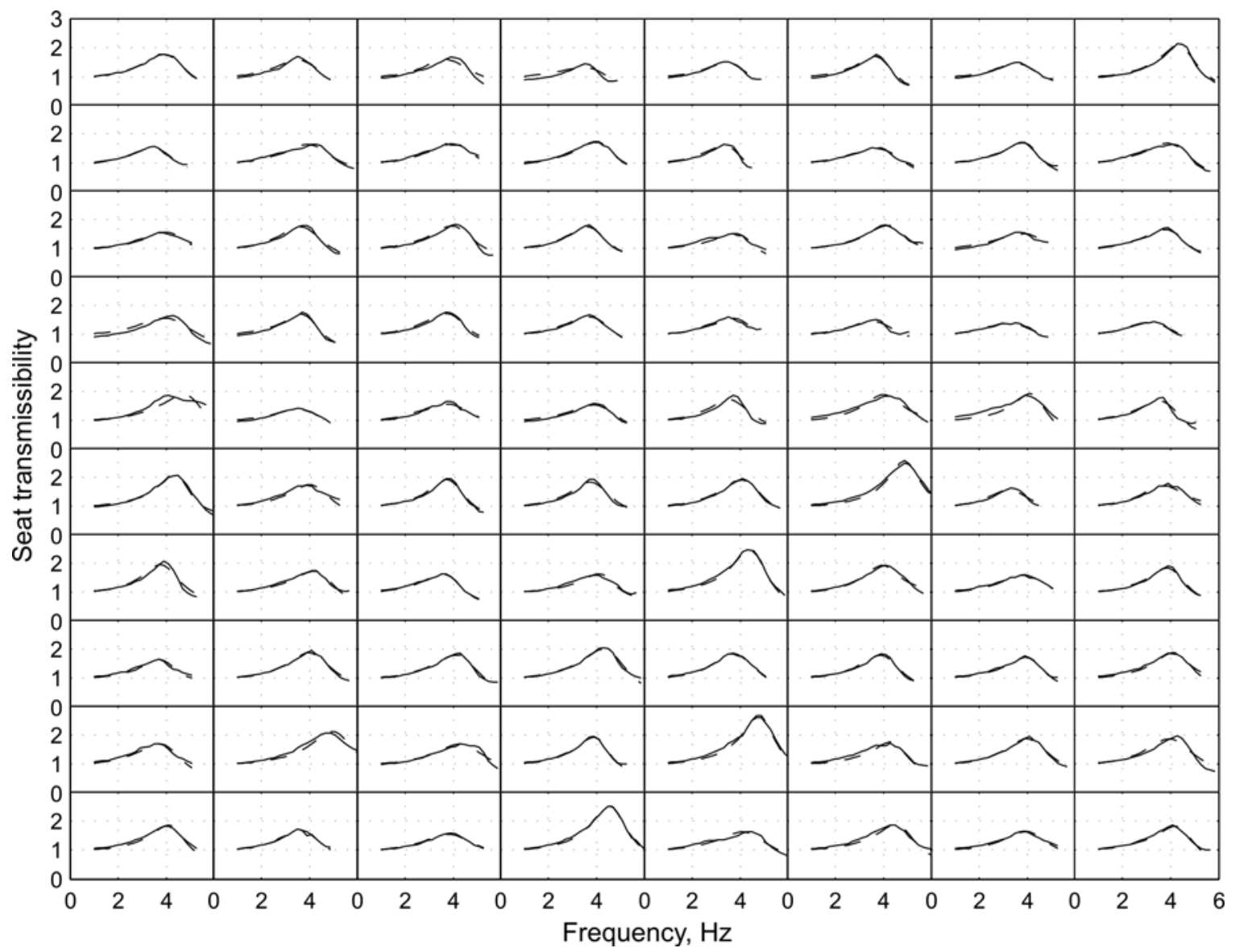

Figure 9 Seat transmissibility (modulus) of 80 people (no backrest; excitation magnitude $1.0 \mathrm{~ms}^{-2}$ r.m.s.). Comparison of measured (- - and modelled (- - - ) data. 


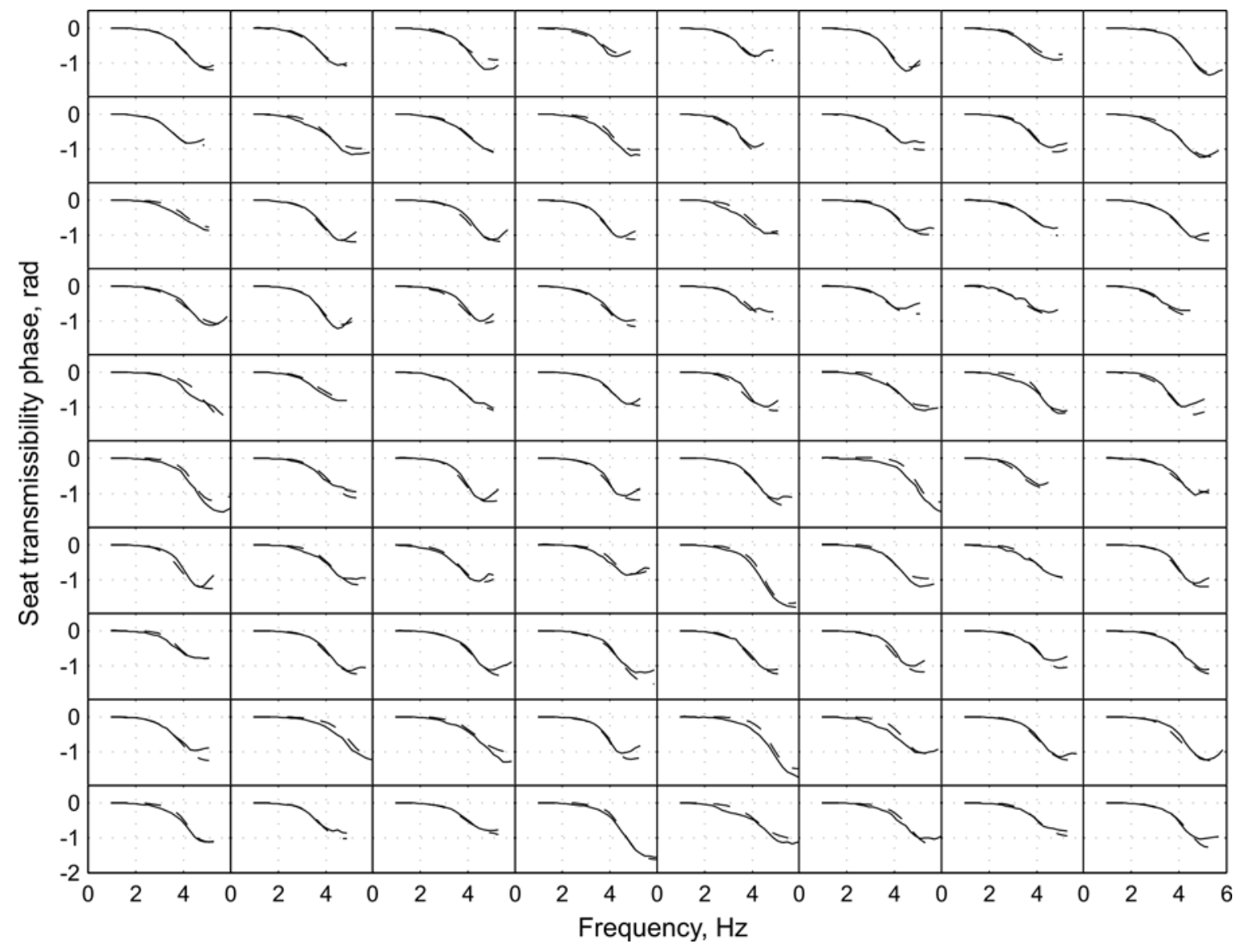

Figure 10 Seat transmissibility (phase) of 80 people (no backrest; excitation magnitude $1.0 \mathrm{~ms}^{-2}$ r.m.s.). Comparison of measured ( - ) and modelled (- - - ) data. 
Published as: The transmission of vertical vibration through seats: influence of the characteristics of the human body. Toward, M. G. R. \& Griffin, M. J. 19 Dec 2011 In : Journal of Sound and Vibration. 330, 26, p. 6526-6543.

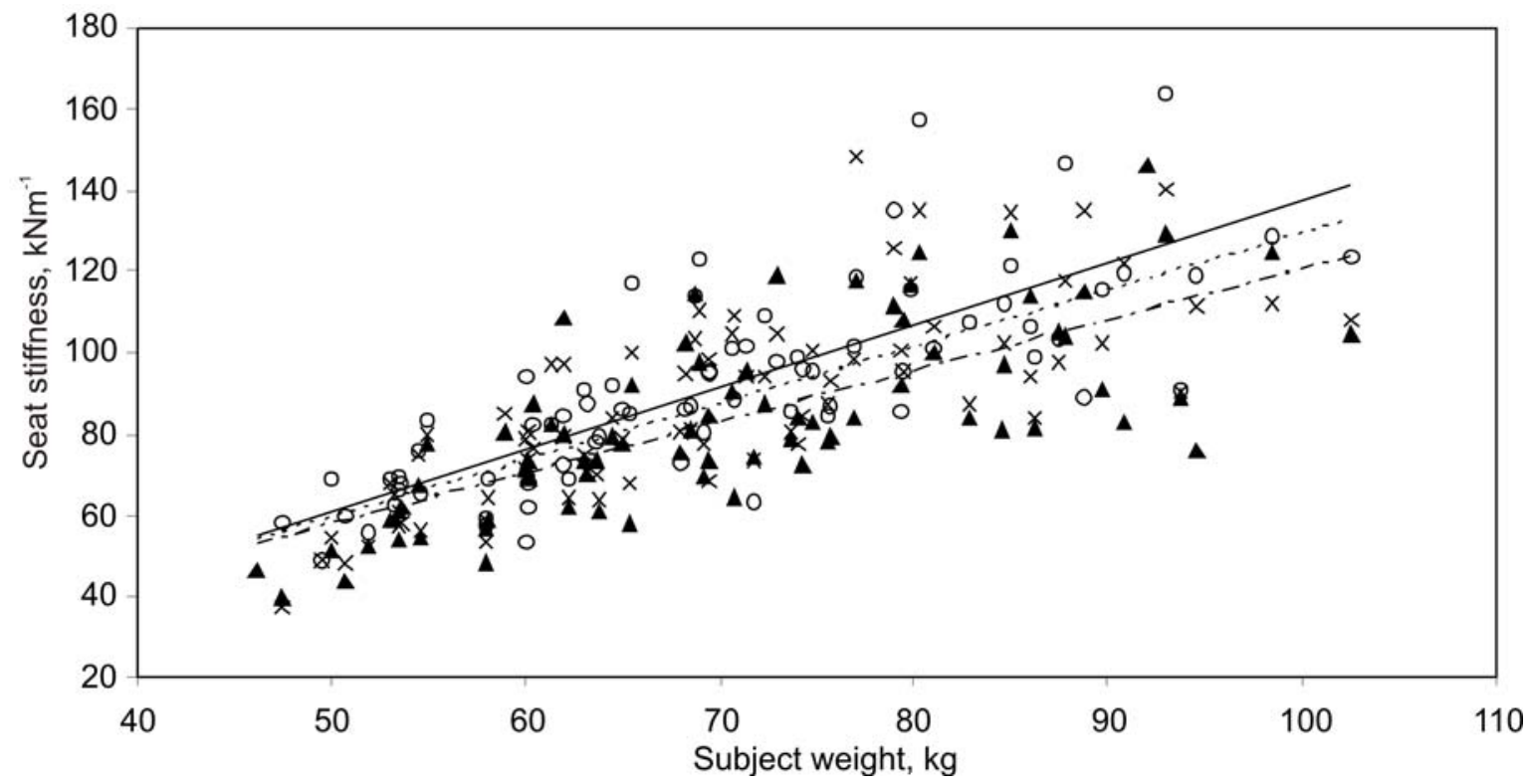

Figure 11 Effect of subject weight on the derived seat stiffness at three magnitudes of vertical vibration excitation (no backrest): $0.5 \mathrm{~ms}^{-2}$ r.m.s. ( $\circ$ ), $1.0 \mathrm{~ms}^{-2}$ r.m.s. $(\times)$ and $1.5 \mathrm{~ms}^{-2}$ r.m.s. ( $\Delta$ ). Bivariate regression trend lines are also shown: $0.5 \mathrm{~ms}^{-2}$ r.m.s. $(-), 1.0 \mathrm{~ms}^{-2}$ r.m.s. $(\cdots)$ ) and 1.5 $\mathrm{ms}^{-2}$ r.m.s. $(\cdot-\cdot-)$. 